\title{
Renegotiating Urban Water
}

Sarah Bell s.bell@ucl.ac.uk

Accepted for publication in Progress in Planning

\begin{abstract}
Water infrastructure is essential for the functioning of modern cities. This paper analyses conventional models of water infrastructure provision and emerging alternatives in order to identify points of reform and resistance in the relationship between people, technology and water in cities. It begins with a review of recent academic contributions to understanding the relationships between people, technology and nature in cities through the analysis of urban infrastructure. The work Andrew Feenberg, a critical philosopher of technology, is presented as the basis for analysing both the technical and discursive elements of infrastructure. Feenberg's concept of 'the technical code' is used to synthesise key insights from the analysis of urban infrastructure and technology, to devise a series of critical categories for comparing changes currently underway in urban water infrastructure provision. This 'technical discourse of water infrastructure' is used to analyse developments in desalination, wastewater reuse, decentralised non-potable supply, domestic water efficiency, water sensitive urban design and ecological sanitation. Planners, designers and policy makers concerned about sustainability should be wary of the technical inevitability of desalination, potable recycling and other systems which reinstate conventional codes of domination and control of nature and separation of public concern from technical rationality. Decentralised water systems embody assumptions about the limits to water resources, but can also be problematic as high users of energy and reinforcing a private right to water. Improving the efficiency of domestic water using technologies and appliances is unarguably important in achieving sustainability. Moving beyond water efficiency to open up discussions about water using practices and cultural norms holds greater potential for transforming water consumption. Water Sensitive Urban Design is widely championed by designers and planners as exemplifying a sustainable approach to urban nature, providing a useful foundation for more moving beyond drainage into water supply and wastewater technology and discourse. Ecological sanitation is filling a basic necessity in developing cities and may be part of a longer term transition to sustainability in developed cities in the future. Eliminating water from sanitation and recovering resources from waste holds the potential to radically reorder relationships between bodies, urban spaces and nature. Relationships between cities, technologies and water are shifting. The extent to which this balance falls in favour of sustainability over coming decades will be determined by political discourse as well as technical innovation.
\end{abstract}




\section{Introduction}

Water is a good servant, but it is a cruel master - John Bullein 1562

Technology is society made durable - Bruno Latour 1991

Negotiating our relationship with water is one of the few essential struggles of human settlement. For millions of people this struggle continues through the daily challenges of finding clean water and keeping dirty water out of their homes and bodies. In developed, modern cities this struggle has been delegated. Armies of engineers marshal legions of pipes and pumps to keep clean and dirty water under control in our cities. Water is disciplined, hidden, serving the needs and fulfilling the desires of modern citizen-consumers. Freed from personal struggle to control water, people living in wealthy cities are able to engage in economic, social and cultural life.

Water is a good servant. Domesticated since ancient times to keep cities and households free from disease, water has served as an everyday agent of purification ever since. With water on-tap in homes, offices, factories and public spaces, people have developed new uses for it that go far beyond basic needs for health and hygiene. As new water using appliances have appeared in homes, the networks of pipes, treatment works and reservoirs have expanded to meet growing demand, and the water has continued to flow. Water infrastructure has transformed social relationships and bodily functions. Controlling water in cities also requires particular modes of political control, to enable financing and governance of infrastructure. Water infrastructure has contributed to the social and political transformation of cities as much as hydrological and bacteriological change.

In cities in the developed world, water that falls on urban roofs and streets has also largely complied with engineering and planning controls. Urban drains have ensured that rainwater flows away as quickly as possible, leaving the urban environment free from surface water, except where designated by urban design. Urban rivers and streams have been mastered and constrained, concreted, covered over and incorporated into drainage and sewerage networks. The water that once seeped into the ground and flowed freely in small streams now rushes through pipes beneath the city, discharging into major water bodies, often bringing contaminants.

Water is a cruel master to those who live outside formal infrastructure systems. Daily routines of water collection and purification and battles with water borne and water-dwelling-vector-borne diseases define life for the urban poor in rapidly expanding cities in the developing world. Life and livelihoods are undermined by scarcity of clean water and abundance of dirty water in slum 
settlements around the world. Such aqueous chaos is usually the result of the absence of infrastructure to control water, rather than absolute water shortages or extreme flood events. Technology, governance, economics and politics are the cause of daily water catastrophes more often than hydrology.

The control of water in cities, along with the construction of canals, roads and railways, was one of the founding tasks of the civil engineering profession. To mark the formation of the Institution of Civil Engineers in 1828 Robert Tredgold defined engineering as 'art of directing the great sources of power in nature for the use and convenience of man'. For almost two centuries engineers have managed water in cities, following principles of control and domination. Where they have succeeded, they have eliminated water-based public health problems and enabled the development of modern lifestyles free from concern about water quality or quantity. The legacy of controlling water for human use and convenience is lost or degraded rivers and aquatic ecosystems, high energy consumption, and the illusion that supply can expand endlessly to meet growing demand.

Modern systems of water control have never been perfect. Despite immense success they are now beginning to unravel. Pressures of population growth, overconsumption and climate change are disrupting once stable relationships amongst engineering systems, hydrological systems, cities and people. Cities such as London, Sydney, Barcelona, Tel Aviv and San Diego have exhausted conventional water resources and are implementing energy intensive desalination and recycling schemes. The continued failure to meet the needs of the world's poorest urban residents is a further indication of the inability of nineteenth century models of infrastructure provision to meet the needs of twenty-first century cities. Torn between the challenges of water profligacy and water poverty, the dominant model of water infrastructure in modern cities is increasingly seen to be deficient. Relationships of control and domination of water, enacted through vast technical systems, designed and managed by engineers, regulated by governments and financed by global capital markets, may no longer be sufficient to ensure safe, liveable and sustainable urban environments.

Urban water problems are social, political, hydrological, cultural, economic and technical. Addressing current challenges requires a broader range of expertise and greater democratic deliberation than has been deployed since the urban infrastructural revolutions of the nineteenth and early twentieth century. Devising sustainable systems for directing flows of water through and within cities requires reconceptualising the nature of infrastructure. 
In reconsidering the form of urban water infrastructure it is timely to reconsider the relationship between cities and water. New configurations of people, pipes and plumbing may allow for water partnerships to emerge out of modern pattern of domination and control. What would a city look like if human relationship to water acknowledged limits to control, and conceived of water as a partner in shaping patterns of settlement and culture rather than a cruel master or a submissive servant?

This paper analyses conventional models of water infrastructure provision and emerging alternatives in order to identify points of reform and resistance in the relationship between people, technology and water in cities. It begins with a review of recent academic contributions to understanding the relationships between people, technology and nature in cities through the analysis of urban infrastructure. The work Andrew Feenberg, a critical philosopher of technology, is presented as the basis for analysing both the technical and discursive elements of infrastructure. Feenberg's concept of 'the technical code' is used to synthesise key insights from the analysis of urban infrastructure and technology, to devise a series of critical categories for comparing changes currently underway in urban water infrastructure provision. This 'technical discourse of water infrastructure' is used to analyse developments in desalination, wastewater reuse, decentralised non-potable supply, domestic water efficiency, water sensitive urban design and ecological sanitation. For each technical proposition technical and policy documents and case studies are analysed, from several countries, mostly focused on the UK, US and Australia. The results demonstrate that water infrastructure is currently undergoing a series of changes, some of which are contradictory and others counterintuitive. Water infrastructure is simultaneously moving towards and away from sustainability, with some trends reinforcing patterns of domination and exploitation of water and nature, while others represent the potential for radical transformation of social, ecological and technological relationships.

The paper brings the technologies of water infrastructure to the fore, simultaneously exposing the competing political, ecological and social values at play in urban water systems. The materiality of water and technologies are presented on their own terms, whilst at the same time they are shown to embody particular sets of values and assumptions about relationships amongst people, and between people and their environment. As the nineteenth and twentieth century models of water infrastructure provision begin to unravel, competing arrangements of technology, space, people and the environment are emerging in cities. This paper looks at particular technologies and strategies, to reveal different technical and discursive constructions of water infrastructures, some of which 
entrench existing patterns of domination of water in cities, others which indicate the possibility of partnership.

\section{Thinking through infrastructure ${ }^{1}$}

To live within the multiple, interlocking infrastructures of modern societies is to know one's place in gigantic systems that both enable and constrain us (Edwards, 2011, p. 191).

Infrastructure systems of energy, communications, transport, water and waste underpin the basic functioning of modern cities, and to a large extent represent the very essence of urban modernity. These systems facilitate or even require lifestyles based on high consumption of natural resources. Infrastructural models established during the nineteenth and twentieth century transformed cities and lifestyles, particularly in developed countries. They were largely developed under the assumption of limitless supply of water, energy and other natural resources and the belief in the ability of engineers to fulfil Tredgold's mandate to continually harness the forces of nature for the benefit of humans. Infrastructures provide an essential coherence to modern life and stabilise ontological relationships between people and nature that are central features of modernity (Edwards, 2011).

Conventional engineering theories of infrastructure largely conform to an instrumentalist approach to technology, which understands technology as humanly controlled and value neutral (Feenberg, 1999). Under this view, infrastructure is an outcome of human planning and design on the basis of objective, technical rationality, and it provides a neutral background upon which culture, society, economy and politics develop. Such accounts usually understand the history of infrastructure development as the outcome of rational planning and technical optimisation. Alternative propositions for particular designs of infrastructure or technology are either forgotten or assumed to have been technically inferior or irrational. The present form of infrastructure is assumed to be the accumulation of technically rational decision making. Where systems fail to meet current standards for environmental protection or social inclusion this is attributed to a lack of knowledge compared with contemporary professionals, or less enlightened society and politics driving engineering design. Accounts of urban water systems commonly hold that nineteenth century engineers designed technically rational solutions to problems of public health, given the state of knowledge an environmental values, and did not have the same knowledge or ethics as twenty first century

\footnotetext{
${ }^{1}$ Apologies to Carl Mitcham (1994) for imitating the title of his seminal book Thinking through Technology Chicago: University of Chicago Press.
} 
engineers regarding the importance of environmental protection and sustainability (Novotny et al, 2010).

By contrast, critical accounts of infrastructure highlight the mutual influence of political and social context, and infrastructure planning and engineering design (Feenberg, 1999). Infrastructure systems embody social and political values and shape urban possibilities. Critical theories of technology and infrastructure draw empirical and methodological support from social constructivist accounts of science and technology, which show the influence of social processes on the production of scientific knowledge and technical artefacts (see for example Bijker, 1995; Latour and Woolgar, 1979).

Water infrastructure systems present specific challenges to engineers, planners and decisionmakers, due to the specific properties of water and hydrological systems, and the challenge of maintaining good public and environmental health. However, the technical and managerial logic of water infrastructure holds much in common with other urban systems, such as energy, transport and waste. Understanding water infrastructures as socio-technical systems that mediate relationships between people and their environment, that enable and constrain particular forms of social life, and that are governed by specific institutions can help to reveal their role in stabilising or disrupting existing constructions of the relationship between city, people and nature.

\subsection{Socio-technical infrastructures}

Infrastructures are in essence large scale urban technological systems. They are material assemblages that comprise the basic technological fabric of the city, delivering essential urban functions. Infrastructures are at the same time intensely social and political, and inseparable from the economy of the city. As such they have been characterised as 'socio-technical systems'. The technologies of infrastructure exist within a broader social and political context, which itself cannot operate independently of infrastructure systems, and so human interests and technical objects become endlessly entwined.

For most of the twentieth century provision of universal access to basic infrastructure was a goal of municipal and national governments (Marvin and Graham, 2003). Access to water and sewerage were deemed essential to good public health. As such the state had a major role to play in the provision and management of infrastructure, which was seen to be a public good. Public investment in infrastructure was thought to underpin economic and social development. Infrastructure networks spread across cities and countries, linking citizens to the benefits of modern technology 
and resources. Such investment depended on governments having ready access to finance to fund the construction and ongoing revenue to fund operation and maintenance.

Since the 1980s changes in public policy associated with neo-liberal ideals of market liberalisation and privatisation have had profound implications for infrastructure provision around the world. Private sector involvement in infrastructure provision expanded considerably in the 30 years prior to the current financial crisis. Infrastructure investment is now seen as a key economic stimulus measure, but often in partnership with private investors and providers rather than through purely public ownership and operation. The move away from state ownership and the goal of universal provision, towards a growing role for the private sector in infrastructure systems at the end of the twentieth century is documented in Marvin and Graham's (2001) Splintering Urbanism. Their work highlights the social, environmental and economic inequities that can become entrenched when access to infrastructure services is based on profitability rather than universality. In many cities it is now possible to observe well connected, middle and upper class suburbs and central business districts with world class access to water and other infrastructure services, side-by-side with slum settlements that have no formal provision. The challenge of providing basic services to the urban poor is made more complex by the often unplanned, illegal status of slum settlements and the difficulty of obtaining finance to build or extend infrastructure systems to low income, less profitable, areas. As a result, the poorest city residents may be forced to pay the highest prices for water, resorting to private or illegal vendors who charge higher rates than the centralised utility (Swyngedouw, 2004; Allen et al, 2006)

Infrastructural systems such as water, energy and waste, are central in structuring modern patterns of consumption of natural resources. In contrast to other forms of consumption, consumption of resources through infrastructure services is inconspicuous, largely unnoticed (Shove, 2003). Likewise infrastructural technologies are largely invisible in cities in the developed world. Infrastructure, and its services and resources form part of the background of everyday life, only entering the users' consciousness when something breaks down, when resources are scarce or when absent altogether (Edwards, 2011). It is the absence of infrastructure in developing countries that is noteworthy, not usually their role in shaping rates of resource consumption in cities where they function effectively. Even in circumstances where resource consumption is of concern, such as during droughts, infrastructure itself is usually spared scrutiny as resources and consumer behaviour, the two ends of the pipe, are subject to increased control and public debate (Bell, 2009). 
Sociologist Elizabeth Shove (2003) points out that water using practices and cultures of cleanliness have changed radically in the recent past and are constantly evolving. She analyses inconspicuous consumption of energy and water in everyday life in terms of the co-evolution of socio-technical systems, consumer habits and norms, and the symbolic and material qualities of socio-technical objects. The provision of continuous piped water and sewerage to private houses coincided with changing social norms of cleanliness and enabled the development of new technologies such as washing machines and showers. In turn, increased demand for water led to further expansion of infrastructures systems, consumers evolved new norms and expectations such as showering as a daily experience of 'comfort' and laundry as the restoration of fabric 'freshness', and new products such as shower gels and fabric softeners emerged. Shove's analysis shows a 'ratcheting up' of consumption through this interplay of systems, technologies and cultures, but also highlights the possibility for radical change in consumption beginning with encouraging diversity in daily practices and norms and the systems and technologies they are enmeshed with. Her analysis shows that just as water flows between public and private realms, so too our intimate practices, habits and expectations which demand high volumes of water are shaped by public, private, cultural and technological forces, and are therefore subject to change.

Since the early 1970s the decentralisation of infrastructure, and associated political and social institutions, has been a common theme in much environmental literature and activism. In reaction to the environmental and social impacts of centralised infrastructure and industrialised society environmentalists have promoted small scale technologies as inherently more ecological and democratic. The 'appropriate technology' movement was inspired by ideas presented in E.F. Schumacher's (1974) classic Small is Beautiful, which challenged the transfer of large scale industrial development to the developing world and called for development that was rooted in local environments and cultures and operated on a 'human scale'. The appropriate technology movement in industrialised economies promotes energy efficiency, renewable energy, composting and other alternatives to centralised infrastructural systems. Decentralisation of technology is usually taken to imply decentralisation of social, economic and political organisation, though this could be to capitalist, socialist or anarchist ends (Winner, 1986).

Van Vliet et al (2005) analyse the role of infrastructure in shaping patterns of consumption, and the potential for alternative configurations of both technologies and institutions, including various arrangements which cut through the conventional dichotomy between centralised and decentralised systems. They reveal a move from centralised infrastructure provision and explore the potential for 
differentiation in infrastructure provision to lead to more sustainable modes of provision. They demonstrate that the scale of management need not match the scale of technologies and service networks. It is possible for small scale technologies to be managed by large scale institutions, and small scale institutions can act as providers and brokers for larger networks of provision.

Susan Leigh Star (1999) presents a definition of infrastructure as a 'fundamentally relational concept, becoming real infrastructure only in relation to organized practice' (p. 380). Infrastructure exists only in the context of its use or as a problem to be solved. The water system consists of multiple meanings and uses, not simply pipes, pumps, valves, taps and treatment works. To the office worker beginning their day water infrastructure is the system that is necessary to take a shower, to the plumber it is a system requiring repair, and to the city planner it is one variable in a complex urban planning process (Star, 1999). Infrastructure embodies particular politics and categories, shaping access and inclusion to society as well as exclusion and 'otherness'. Langdon Winner's (1986) contested analysis of Robert Moses design of traffic bridges at such a low height as to effectively exclude public buses, hence poor people, from the Parkways which allowed access to the Long Island suburbs, has become a classic example of how infrastructures stabilise particular social relationships and embody dominant values.

\subsection{Infrastructures of domination}

Infrastructure has been essential in formalising and stabilising urban order, disciplining nature by controlling flows of water, waste and energy, and underpinning patterns of human movement and habitation. Paul Edwards points out the relationship of domination between humans and nature that is embodied in modern infrastructural systems:

to construct infrastructure is simultaneously to construct a particular kind of nature, Nature as Other to society and technology (Edwards, 2011, p. 189)

Infrastructure systems are associated with masculine constructions of technology and engineering (Wajcman, 1991). Masculine association with infrastructure as technology include an obsession with control and power, and the pre-eminence of 'hard' technical solutions over 'soft' social processes. Whilst engineering work, like gender, rarely conforms to such stereotypical binaries, the social construction of gender, engineering and infrastructure is shaped by persistent cultural associations between women and nature, and men and technology.

The scale of infrastructure provision is in sharp contrast with the everyday experiences of users as they consume water, energy or other services. Zoe Sofoulis (2005) has coined the term 'Big Water' 
to refer to the scale and vision of water infrastructure provision and management in Sydney, Australia. Big Water consists of engineering systems and visions based on 'nation-building' dam construction projects, vast treatment works and distribution systems. This is in stark contrast to the 'Everyday Water' experience of household water use in Sydney. Water use is central to some of our most private and intimate activities - going to the loo, showering, bathing children or tending a family garden. Messages that 'Big Water' resources are running out and users need to change their behaviour to conserve water rarely account for the details of everyday water use. Furthermore, household fittings and appliances designed in line with the Big Water promise of endless supply are not easily adapted to support water saving efforts by conscientious householders. In studies by Sofoulis and others water users have shown tremendous willingness to change their behaviours to conserve water, but the technologies and infrastructure of water provision are rarely available to support their efforts (Allon and Sofoulis, 2006; Doron et al, 2012; Sofoulis, 2005). Such changes in behaviour remain outside cultural norms and without supportive technologies and infrastructures.

The confrontation of 'Big Water' and 'Everyday Water' presented by Sofoulis points again to fundamental tensions and contradictions within the dualistic structures of modern infrastructure, institutions and society. Big Water is an essentially engineering led approach to controlling water in cities. Even in the early decades of the twenty-first century the engineering profession remains dominated by men, as does the management of water utilities. This is despite higher than average participation by women in engineering disciplines associated with water infrastructure, such as chemical, civil and environmental engineering. Notwithstanding genderless needs for bathing and toilet flushing, Everyday Water remains largely the domain of women. This is consistent with nineteenth century divisions of labour, urban space and governance. Whilst women have made considerable in roads into other areas of public life and gender relationships have undergone significant transformations, water infrastructure remains a largely masculine domain. The consumption of water is associated with private, feminine activities and spaces, and the production of water remains a highly technical, masculine, public activity (irrespective of whether the utility is owned by government or private capital).

Feminist urban scholarship uncovers the complexity of gender relationships and power in cities, including constructions of public and private space (Watson, 2002). Feminists have shown the problematic constructions of gender within the modern city, particularly in relation to women's capacity to engage in urban public life. 
Architecture and urban planning have orchestrated the separation between women and men, private and public, home and paid employment, consumption and production, suburb and city. While people do not actually live according to these dichotomies, the widespread belief in them does influence decisions and have an impact on women's lives (Wajcman, 1991, p. 110).

The provision of clean water and sewerage services to homes via urban infrastructure systems has had very important benefits for women. Piped water reduces the burden of sourcing and carting water, hot water systems reduce effort spent heating water and carting it within the home, and improved standards of cleanliness and hygiene reduce illness and the work of caring for sick. However, water systems have also created new work in the home which has largely been taken up by women (Schwartz Cowan, 1983). According to Ivan Illich, the water systems and social change of the nineteenth century reformulated deeply held cultural associations between women and water: water, which has always been perceived as the feminine element of nature, in the nineteenth century was tied to a new "hygienic" image of woman, which was itself a creation of the Victorian age (Illich, 1986, p. 1).

The modern city also provides opportunities and freedoms for women. Elizabeth Wilson's (1991) Sphinx in the City is a compelling account of women's freedom and discipline in cities including London, Paris, New York, Chicago, Sao Paolo and Accra. She shows how changes in urban governance, culture and form impact on women's particular experience of the city. For instance, the sanitary movement in nineteenth century London led to the provision water and sewerage infrastructure which undoubtedly improved women's lives, but was also associated with a culture of urban control and discipline which limited women's ability to engage in public life and paid work. Patterns of control over women, workers, nature and others came to characterise the modern city, as Wilson sums up:

The story of the nineteenth- and twentieth- century city is largely of the triumph of intervention and mastery over appreciation and immersion (Wilson, 1991, p.25).

The patterns of control and discipline that emerged in modern cities and are exemplified by water and other infrastructure conform to structures of dualism analysed by ecological feminist scholars such as Val Plumwood (1993), Carolyn Merchant (1990) and Karen Warren (1987) who link the domination of masculine over feminine to the domination of nature. The feminine is associated with the body, emotion, nature, privacy and invisibility, while the masculine is celebrated along with the 
mind, reason, culture, public life and visibility. Ecological feminist activism aims to overturn and disrupt the culture of domination of both women and nature, and has been important in urban environmentalism, the peace movement and in linking nature conservation to the livelihoods of poor women in developing countries (Mies and Shiva, 1993; Shiva, 1989).

Pointing out an association between masculine domination of water in public, engineering led utilities, and the feminine, private experience of everyday water is not to blame men for water shortages nor to suggest that water consumption would be any different if they did more housework. Nor is it meant to imply that women engineers would design or manage infrastructure systems more sustainably. It simply demonstrates the persistence of patterns of domination and dualism, reflected in the systems and spaces of the modern city. This means that devising urban water systems that function in partnership with natural systems may require transformation of urban politics and culture and deep questioning of taken for granted practices and norms in public and private life.

Breaking through associations between masculine, public, cultural, visible and technical; and feminine, private, natural, invisible and social will be fundamental in developing new socio-technical systems that both meet human and environmental needs for water on the basis of understanding water as a partner in urban planning rather than a servant or master. Water flows between dualistic categories of domination, appearing in public and private, as cultural product and natural environment, as object of rational planning and subject of bodily pleasure. As such a more ecologically sensible and socially just approach to water in cities needs to acknowledge these multiple flows of water and their relationship to social life in devising systems that are not based on domination and control of people and nature.

Recent feminist theory which draws on post-structuralist and post-modernist ideas provides the basis for strategies that respond to multiple and diverse experiences and constructions of nature and gender in cities (Watson, 2002). Moving beyond the monolithic constructions of gender and urban space in terms of structures of dualism, more recent approaches acknowledge the fragmentation and multiplicity of women's experience of cities. This leads to greater complexity and finer nuance in framing questions of gender in cities and a wider range of strategies and outcomes to ensure women's experience and interests are accounted for in decision making, design and urban life. 
The work of Donna Haraway has been important in developing theoretical and analytical strategies for feminist studies of technology that point out the political implications of dominant forms technoscience whilst also providing opportunities for women, workers and others whose interests are marginalised to deploy the increased blurring of distinction between nature and technology for subversive ends. Her 'Cyborg Manifesto' (1991) has played a central role in feminist theory of technology, and has been used in urban political ecology, to move beyond classical dichotomies such as nature and culture, body and mind, feminine and masculine, technology and biology. Haraway's analysis is based on a literal, critical materiality, which has been characterised as material semiotics. As she writes,

Understanding the world is about living inside stories. There's no place to be in the world outside of stories. And these stories are literalized in these objects. Or better, objects are frozen stories. Our bodies are a metaphor in the most literal sense. This is the oxymoronic quality of physicality that is the result of the permanent co-existence of stories embedded in physical semiotic fleshy bloody existence. None of this is an abstraction. (Haraway, 2000, p. 107)

\subsection{Nature, power and technology in cities}

Matthew Gandy (2005) draws on Haraway's (1991) cyborg amongst others to develop a theory of cyborg urbanisation. Gandy uses the figure of the cyborg as both an ontological strategy and a trope for critical reflection on urban phenomena that are not adequately accounted for in urban and architectural studies. The cyborg breaks through conventional distinctions between body and machine, real and virtual, nature and culture, and as a spatial metaphor provides the possibility for radical politics which disrupt conventional discursive and material arrangements. Gandy analyses urban infrastructure as cyborg in order to explore the relationships between the city, bodies and the human subject. The analysis uncovers a blurring of the boundaries between mind, city and body, fears of the autonomous progress of technology into the realm of the body and biology, optimism at the prospect of post-human liberation, and an alternative construction of human agency as enabled and constrained by the material relationships that constitute increasingly fractured political and social life in the cyborg city. Gandy uses the co-evolution of water infrastructure, personal hygiene and governance of water utilities as an example of the complex relationships that constitute urban life and do not correspond to conventional demarcations between bodies, nature, infrastructure, politics, culture, architecture and so on. His analysis leads to a call for greater attention to the politics of technology in the city and the reformulation of the public sphere to account for the hybridity of cities and subjects. 
Water infrastructure is a critical concern of urban political ecology, not only as a vital element of cities in itself, but also as an exemplar of the complex relationships and flows between nature, culture, technology, politics and bodies in cities. Swyngedouw's (2004) account of the unequal access to water infrastructure in Guayaquil, Ecuador describes the processes and structures of exclusion from basic public health infrastructure, including the problematic role of private capital and neo-liberal policy agendas in water provision. Gandy's (2008) analysis of water infrastructure in Mumbai highlights similar factors at work in the continued failure of governments and private utility companies to deliver water to the urban poor, alongside the delivery of world-class services to wealthy districts in the city. Maria Kaika (2005) traces the changing relationships between people, technology, governance and water in Athens from the early $19^{\text {th }}$ to the late $20^{\text {th }}$ century. She highlights three key movements in the construction of nature reflected in the development of water infrastructure - nature a source of wonder and danger, nature as tamed by modern infrastructure, and finally nature in crisis.

Karvonen $(2010,2011)$ analyses the history of water management, governance and engineering in Austin and Seattle as a means of understanding changing relationships between citizens, politics, technology and nature in the city. In Seattle he shows a shift from a 'Promethean' approach toward a more sustainable future, involving changing forms of expertise, governance and citizenship. Karvonen's choice of water as the medium through which to tell the story of changing relationships between citizens, the municipality and the natural environment is prescient. However, it is significant that water supply and sanitation feature in his description of the early Promethean era of municipal engineering and 'city building', while his case studies of recent shifts towards a more ecologically sound approach to urban nature pertain exclusively to surface water drainage. During the nineteenth and early twentieth centuries Seattle's relationship with water and nature was one of domination, changing landscapes and building public health and drainage infrastructure. More recently the 'Metronatural' Seattle has moved towards a partnership approach to nature, bringing water back into the urban environment through new drainage strategies and urban design. Seattle has also undertaken a comprehensive water demand management campaign but private relationships to water, mediated through water supply and sanitation infrastructure, remain largely undisturbed.

Nature, gender, technology, culture, politics and society all intertwine in cities. The sustainability of urban systems is an outcome of these complex networks of relationships, which can be difficult to trace through different theoretical and critical perspectives. Patterns of resources use are shaped by 
patterns of social relationships, infrastructure and technology. Moving towards more sustainable water use and drainage in cities requires knowledge of how these different factors influence current water systems and proposals for new technologies and infrastructures. A workable framework for urban planners, designers and engineers to analyse current and future infrastructure patterns requires grounding in both theoretical analysis of the relationships between technology, nature and society, and practical application to guide design and decision making.

\section{Technology, values and water}

A framework for analysis of infrastructure, design and decision making must acknowledge the sociotechnical nature of infrastructure, uneven power relationships in cities, and the role of nature as both resource and active constituent. For planners, engineers and designers, it is also important that such analytical framing provides the possibility for alternative futures, and the opportunity to achieve normative goals such as sustainability and justice. The work of philosopher of technology Andrew Feenberg and his idea of 'the technical code' provides a foundation for identifying the discursive, political and technical nature of infrastructure in cities. Feenberg's analysis has focused on technology, and may be extended to address infrastructure as large technological and discursive systems.

\subsection{The Technical Code}

Feenberg's critical theory of technology draws attention to the political and social values that are intrinsic to modern capitalist technologies and industrialisation, and he maintains the possibility that alternative political and technical arrangements are possible -

social purposes are "embodied" in the technology and are not therefore mere extrinsic ends to which a neutral tool might be put. The embodiment of specific purposes is achieved through the "fit" of the technology and its social environment. The technical ideas combined in the technology are neutral, but the study of any specific technology can trace in it the impress of a means of social determinations which preconstruct a whole domain of social activity aimed at definite social goals (Feenberg, 1991, p. 81).

Feenberg (1999) develops a theory of the dual nature of technology - technology as function and meaning. Feenberg maintains the primacy of human will and politics in determining the structure of technological society. Modern technological society has been dominated by capitalist politics, but this is historically contingent rather than inevitable. Alternative technologies and systems are possible, but must be accompanied by political reform. The appearance and diffusion of alternative technologies without institutional and political reform will undermine their capacity to liberate 
people and the environment from the dominating forces of capitalism. Feenberg remains insistent that political change in turn requires technological change, as political values are stabilised in technologies.

The essence of the relationship between technology and society is formalised in Feenburg's idea of the 'technical code' which -

describes the congruence of a social demand and a technical specification. It is generally materialized in two different ontological registers: discursive and technical. A process of translation links the two... technology and society are not alien realms as are facts and values in the treatises of philosophers. Rather they communicate constantly through the realization of values in design and the impact of design on values (Feenberg, 2010, p. 68).

The technical code can be used to frame choices between technically feasible design alternatives, stabilising a particular ideology in technically coherent solutions to specific problems. It is the 'rule under which technologies are realized in a social context with biases reflecting the unequal distribution of social power' (Feenberg, 2010, p. 65).

Feenberg translates Thomas Kuhn's (1962) basic thesis from Structure of Scientific Revolutions to the realm of technology. Kuhn's scientific paradigm is equivalent to Feenberg's technical code. Just as anomalies emerge in established scientific paradigms pre-empting paradigm revolution, so too do anomalies in technical systems lead to revolutionary changes in technical codes. The concept of the technical code has direct regulatory resonance to planners and engineers, but can also be extended to encompass the paradigmatic nature of models of infrastructure provision beyond the details of design and regulation.

\subsection{The technical discourse of water infrastructure}

The technical code of water infrastructure is comprised of technical and discursive elements. The meaning and values embedded in infrastructure systems can be considered under distinct categories to allow comparison between alternative systems. Based on critical and ecological analysis of technology and infrastructure, the categories for analysing the technical discourses of water infrastructure are: water itself, nature, technology, governance, society, capital and space.

Water itself as a material element and discursive construction must be central to analysis and decision making about water infrastructure. In critical accounts of water infrastructure the details of quality and quantity of water are often overlooked as water is analysed as a signifier of political and 
social power relationships. Different technologies embody distinct assumptions about the materiality and ecology of water itself, which provides a crucial starting point for analysing infrastructure.

Water is a natural resource and important component of natural environments. Water infrastructure systems consume energy resources and discharge pollutants to the natural environment. Water infrastructure and technologies embody particular assumptions and values about the wider relationship between people, cities and the natural environment, providing key insights into their potential for sustainability.

Water infrastructure is a vast socio-technical system, and alternative scales and complexities of technology have been proposed to address the challenge of sustainability. Technology choices are framed by assumptions about the nature of technical risk, control, operation and maintenance. These assumptions have important implications for the nature and role of technical expertise in designing and delivering water infrastructure, ranging from simple lay systems to complex sociotechnical infrastructures.

The close relationship between governance and infrastructure provision are well documented. Infrastructure projects shaped governance structures in cities, and failure of infrastructure projects is often attributed to governance failures. However, the relationship between democracy and infrastructure provision is often contested. Infrastructure systems embody particular assumptions about the nature of urban decision making, power and democracy, which do not necessarily correspond to the scale of technology.

The co-evolution of social practices, values, consumption and technology is underpinned by the provision of water infrastructure. Infrastructure systems embody and enable particular patterns of social organisation including gender, social equity and resources consumption. Whilst the details of these complex relationships are difficult to unravel it is possible to highlight key discursive assumptions about the nature of social relations upon which a particular model of infrastructure provision is based.

Capital investment in infrastructure is one of the most contentious elements of public policy. Ownership and investment by public and private capital, and financial structures are the subjects of intense economic and political debate. As alternative models of infrastructure provision emerge, 
different models of ownership and investment, and different intensities of capital investment become apparent, with a range of scales of investors, owners and financers possible in providing water systems and services in cities.

The spatial distribution and location of water infrastructure are fundamental to urban form and function. The relative visibility of water of different quality and functions within the urban environment, and the distribution of sites of water production, consumption are emblematic of wider relationships between technology and society, and nature and the city. New models of infrastructure provision both challenge and reinforce conventional distribution of water and water technologies throughout the urban environment and the relationships between cities and their wider hydrological regions.

The categories of a technical code, or technical discourse, for water infrastructure can form the basis of comparing the technical and discursive propositions for alternatives. It can also be used to analyse the dominant model of water provision and to define a normative ideal sustainable water system (Table 1).

Table 1. Technical discourse of water infrastructure: conventional and sustainable systems

\begin{tabular}{|c|c|c|}
\hline & Conventional System & Sustainable System \\
\hline Water & $\begin{array}{l}\text { Limitless } \\
\text { Pure or contaminated } \\
\text { Dangerous }\end{array}$ & $\begin{array}{l}\text { Freshwater is scarce } \\
\text { Water is multiple and variable quality } \\
\text { and uses }\end{array}$ \\
\hline Nature & $\begin{array}{l}\text { Resource } \\
\text { Sink for waste } \\
\text { Must be controlled }\end{array}$ & $\begin{array}{l}\text { Partner } \\
\text { Limits to material and energy use } \\
\text { Restored and protected }\end{array}$ \\
\hline Technology & $\begin{array}{l}\text { Universal standards } \\
\text { Big systems } \\
\text { Requires expert knowledge }\end{array}$ & $\begin{array}{l}\text { Context specific } \\
\text { Variable scale } \\
\text { Lay and expert knowledge required }\end{array}$ \\
\hline Governance & $\begin{array}{l}\text { Expert led decision making } \\
\text { Large utilities (public and private) } \\
\text { Independent regulation }\end{array}$ & $\begin{array}{l}\text { Democratic } \\
\text { Public participation and engagement } \\
\text { Adaptable to technology and scale }\end{array}$ \\
\hline Capital & Capital intensive & Affordable and appropriate \\
\hline Society & $\begin{array}{l}\text { Consumption is private } \\
\text { Infrastructure serves society }\end{array}$ & $\begin{array}{l}\text { Consumption is cultural } \\
\text { Infrastructure shapes society }\end{array}$ \\
\hline
\end{tabular}




\begin{tabular}{|l|l|l|}
\hline Space & Centralised & Multiple scales \\
& Invisible & Distributed \\
& Outside urban form & Visible \\
\hline
\end{tabular}

\subsection{Infrastructural revolutions}

Technological revolutions look irrational at first, but in fact they establish another framework of rationality, another paradigm (Feenberg, 2010, p. 45).

The challenge of reforming urban water infrastructure is made more difficult as it is literally built in to cities and buildings. Reform of existing water using practices, cultures, infrastructure technologies seems an overwhelmingly difficult task given the capital intensity of the system which is firmly embedded under streets and behind walls, and the mindlessness of most water using practices. However, just as Kuhnian scientific paradigms are subject to anomalies prior to revolutionary change, according to Feenberg technological revolutions may be possible as previously stable models of infrastructure provision are increasingly demonstrated to be inadequate in addressing current and future needs (Feenberg, 2010; Kuhn, 1962).

Recent anomalies undermining the established paradigm of urban water management and forming the basis of new discourses include urban water shortages, climate change uncertainties, rapid urban population growth, persistent failure to deliver water and sanitation services to the global urban poor, and controversy over desalination and potable water reuse schemes. These challenges are often construed as problems of resource and infrastructure management, but increasingly are pointing to the need for deeper reform in models of water and sanitation provision, particularly if sustainability is to be achieved.

The current changes underway in water and sanitation infrastructure and engineering have been presented as the latest in a series of paradigms or stages of development of urban systems. Brown et al (2009) analyse the history of urban water management in Australian cities and identify six regimes beginning with early European settlement and projecting into the future. The regimes are overlapping, each encompassing the previous stages, indicating accumulation of knowledge, technologies and techniques of water management and of socio-political demands. The regimes are the water supply city, the sewered city, the drained city, the waterways city, the water cycle city and the water sensitive city. 
Brown et al (2009) position most Australian cities between the 'drained' and 'waterways' city, moving from attention to supply, sewerage and drainage towards greater consideration of the environmental values of urban waterways, including increased environmental protection and restoration. Current and future research and development are focused on moving towards the water cycle city and water sensitive city, with limited evidence that these are being achieved yet. The water cycle city addresses the goals of integrated water management, analysing water supply, sewerage and drainage systems together to maximise opportunities for sustainability and efficiency of resource use. The water sensitive city brings water to the heart of urban design and planning, such that it is addressed as a fundamental element of the city rather than a separate service or threat that must be managed in order to support other urban functions.

Novotny et al (2010) also take a historical view of the development of urban water systems, identifying four historical paradigms from ancient times to the modern era. The historical paradigms of urban water management are: basic water supply; engineered water supply and runoff conveyance; fast conveyance with no treatment; and fast conveyance with end of pipe treatment. They also outline an emerging fifth paradigm of sustainability which will lead to the creation of water-centric ecocities. Similarly to Brown et al (2009) their depiction assumes accumulation, rather than Kuhnian step-changes, of knowledge and socio-political drivers towards better public health, environmental performance and sustainability.

The narratives of Brown et al (2009) and Novotny et al (2010) demonstrate distinct stages of urban water infrastructure. However, they imply an inevitable achievement of sustainable outcomes as the natural outcome of the accumulation of scientific and technical knowledge and development of new techniques in response to social and political demands. In focussing on environmental improvement and sustainability they overlook counter trends in urban infrastructure provision, particularly the increasing implementation of desalination. Despite dramatic improvements in efficiency in recent years, desalination remains the most energy intensive and expensive technology for water supply, yet it is being widely implemented in cities facing water shortages around the world. Whilst the move to more sustainable drainage and water supply systems can be seen as a response to sociopolitical drivers for improved environmental performance, desalination is a response to an alternative set of drivers to continue to meet demand for fresh water, using capital and energy intensive technologies, with no disruption to consumers or the urban environment. 
Cities are currently experiencing a multitude of responses to the anomalies challenging the dominant technical discourse of water infrastructure. Some of these technical responses demonstrate sustainable values and ideologies, whilst others entrench existing discourses of water and infrastructure. The response of the established water industry to the challenge of water shortage and population growth has been characterised as the twin-track of expanding supply and reducing per capita demand. Demand management is focussed predominantly on technical water efficiency and behaviour change, with growing recognition of the relationship between technology and behaviour. Options for expanding supply include building reservoirs, long distance water transfers and energy intensive desalination and recycling. The twin-track approach fails to recognise the relationship between supply and demand, and the role of infrastructure provision in shaping patterns of demand for resources highlighted by Shove (2003), van Vliet et al (2005) and Sofoulis (2005).

Feenberg shares Brown et al (2009) and Novotny et al's (2010) optimism that current changes in technology and infrastructure will come to embody a more environmentally focussed set of values It seems likely that the ideological form of environmental values is temporary. These values will be incorporated into technical disciplines and codes in a technological revolution we are living unawares today (Feenberg, 2010, p 43)

However, while it may be possible to outline a normative technical discourse for sustainable water infrastructure, it is far from clear that this will be stabilised. If water infrastructure is currently undergoing a revolution as a result of increasing anomalies challenging dominant modes of provision, then it is not possible in the midst of such change to be certain of the form of future stable technical codes. It is however, possible to analyse trends and emergent technical discourses to determine the extent to which they are likely to achieve the goals of sustainability.

It is also likely that the future of water infrastructure provision will be more an order of magnitude more complex than current systems (Bell, 2012). Emerging water infrastructure systems involve many different technologies, systems, institutions, actors and sources of water than current systems. It is possible that there will be multiple technical codes for water infrastructure existing within one city, consistent with post-structural trends recounted in splintering urbanism, cyborg urbanism and feminist theories which emphasise the multiplicity of urban experience, form and function.

Responses to the anomalies challenging conventional infrastructure systems range in scales and technical complexity. The experience of transition is that multiple technical discourses are co- 
emerging, with many different actors, interests and technologies involved. Recognising that water infrastructure is socio-technical, starting with leading technological options as they are currently presented and analysing the discourse and ideology they materialise provides a strategy for identifying emerging and competing technical codes. It also allows comparison of the emerging technical discourses against a normative goal of sustainability, incorporating social, political and spatial concerns that move beyond conventional efficiency indicators.

The major responses to the challenges to water infrastructure that will be considered are: desalination, wastewater reuse, greywater reuse, rainwater harvesting, domestic water efficiency, water sensitive urban design and ecological sanitation.

\section{Desalination}

Water utilities in well-functioning cities have an obligation to maintain continuous supply of clean water to all consumers. When conventional water resources are limited utilities must consider alternative water sources and treatment technologies to avoid the risk of interrupting supply. Water resource planning is rightly risk averse. Infrastructure systems are designed based on historical rainfall records and economic and demographic forecasts of demand for water. Climate change uncertainties make water resource planning more complex. Water resource managers and water utilities in cities such as Sydney, Tel Aviv, London and Tianjin have recent faced prolonged dry periods which push the limits of existing systems to meet demand for water within safe operating margins. In these cities desalination has been investigated and implemented as new, reliable sources of water, at considerable expense and expenditure of energy compared with conventional water resources.

Desalination has traditionally been based on distillation, but growth in desalination is mostly predicated on reverse osmosis, which is also central to most potable reuse treatment systems (Pike Research, 2010). Reverse osmosis is energy intensive, and the energy intensity increases with the level of contaminants in the raw water source (Table 2). Desalination is the most energy intensive, as it uses saline or brackish water as its source.

Table 2. Energy intensity of water treatment technologies (Source: Cooley and Wilkinson, 2012)

\begin{tabular}{|l|l|}
\hline Treatment Technology & Energy Intensity (kWh/ML) \\
\hline Conventional drinking water treatment & $32-530$ \\
\hline Recycled water using membranes & $845-2,200$ \\
\hline
\end{tabular}




\begin{tabular}{|l|l|}
\hline Brackish water desalination using membranes & $790-2,200$ \\
\hline Sea water desalination using membranes & $>3,100$ \\
\hline
\end{tabular}

Global desalination capacity is currently estimated to be growing at $9 \%$ per year, with $54 \%$ of growth between 2010 and 2016 predicted to be in the Middle East and North Africa region (MENA). Total capacity is forecast to grow from less than 80 million $\mathrm{m}^{3} / \mathrm{d}$ to more than 120 million $\mathrm{m}^{3} / \mathrm{d}$ in 2016 (Pike Research, 2010). Desalination has long been prevalent in MENA countries which are rich in energy resources but poor in water, largely based on distillation technologies. Future growth in the MENA region as elsewhere is likely to use reverse osmosis, which is less energy intensive. Strong growth in desalination is forecast in the USA, China, Australia and Israel, with capacity also growing in India, Spain and several other countries.

The technical promise of reverse osmosis is that all water can be made fit for human consumption. Water supplies can be freed from hydrological limits. It has been assumed that less than $0.01 \%$ of all the global water store is available as freshwater for human use, given that $96.5 \%$ of all water is in the ocean and $69 \%$ of freshwater is frozen and 30\% is groundwater (Shiklomanov, 1993). With reverse osmosis, the water that is available for human use is vastly expanded, including practically all the liquid water on the surface of the planet. Whilst the hydrological cycle constantly recycles and purifies water, reverse osmosis and microfiltration allow water utilities to short circuit this natural system.

The promise of purity comes at a high thermodynamic cost. Creating order from chaos, making salty water pure, requires considerable energy. Isolated desalination plants such as those in London and Sydney have addressed sustainability concerns by powering their systems with renewable energy. However, in the broader industrial context, using renewable energy to meet unprecedented demands from energy intensive desalination plants displaces urgently needed reductions in overall carbon emissions. The UK water industry uses roughly $3 \%$ of generated electricity and in the US water related energy use is responsible for nearly $5 \%$ of all greenhouse gas emissions (Rothausen and Conway 2011). In the transition to a sustainable low carbon economy, water utilities, like all industries, would be reducing total energy use and switching to renewable energy, not simply using renewable energy to justify increased energy consumption. More fundamentally, the Promethean vision of turning salt water into fresh perpetuates a culture of consumption without limits and ignores wider environmental impacts of high water consumption, such as the energy required for wastewater treatment and the ecological impacts of wastewater discharges. 
The move to desalination constructs freshwater as an industrial product, which can be manufactured by purifying a raw material of contaminants. Fresh water is a limited resource, but limits can be overcome by technological advances which enable exploitation of water resources that were previously uneconomic to abstract. This is consistent with the conventional theory of economic substitution - as demand for a scarce resource increases and technology develops, previously uneconomic reserves become viable alternative supplies. The increased cost of 'manufactured' water is met by consumers or government subsidies and the direct beneficiaries of capital investment in new technologies are technology suppliers, engineering consultancies and utilities. Reverse osmosis and filtration technologies perpetuate the view of nature as resource for human use, with both energy and water essentially limitless.

With more industrial sources of potable supply, water infrastructure technology becomes increasingly complex requiring higher levels of technical expertise to design and operate. Management of water systems remains in the hands of large utilities, with a strengthening role for global engineering firms and technology suppliers. Consumption of water remains a private affair, and implementation of desalination assumes limited capacity to reduce demand for water. In any case, water demand reduction is much more uncertain than the designed output of a reverse osmosis plant. In highly risk-averse water infrastructure management, desalination is a very reliable way to avoid a deficit between supply and demand that could be harmful to public health. Desalination maintains conventional spatial arrangements of water infrastructure, with water and wastewater treatment works on the outskirts of settlements, but with new technologies increasing the volume available to flow through the system.

Desalination has to be controversial in many parts of the world, largely focussed on the energy intensity, cost and local environmental impacts. Thames Water's proposal for a desalination plant in London was originally denied planning permission on the basis of climate change impacts and the need to consider recycling and reduce leakage as alternative options. A change of mayor quickly resolved the dispute in Thames Water's favour, and the plant was commissioned in 2010, but the conflict demonstrated limits to the public acceptability of technology choices for water treatment.

\section{Wastewater reuse}

Municipal wastewater provides a potential resource under conditions of water scarcity. Wastewater is used for either potable or non-potable purposes, with implications for the technology and energy used in treatment, risk management and public acceptability. 
Potable recycling is less energy intensive but more socially controversial than desalination as it uses treated wastewater as its source. In potable recycling waste water is treated by membrane technologies, usually reverse osmosis. Until recently most potable reuse schemes have been 'indirect', with treated wastewater being mixed drinking water resources in an aquifer, stream or reservoir, prior to conventional treatment. 'Direct' potable reuse, where treated wastewater is returned to the drinking water treatment and distribution without an environmental buffer, has recently been proposed and implemented in the USA in response to serious drought conditions. Indirect reuse has been the preferred option as it is considered to be less controversial and to reduce risks of micro-contaminants recirculating in the drinking water system.

Non-potable recycling of wastewater uses water that would otherwise be discharged to the environment, which has been treated to a standard that is safe for human contact but not human consumption (Gikas and Tchobanoglous, 2009). Irrigation of municipal playing fields, gardens and golf courses with wastewater discharge has been practiced in Australia and the US for several decades, and Israeli agriculture is highly dependent on treated wastewater. More recently in Europe and Australia housing and public space developments have been built with dual plumbing systems the standard drinking water supply and a second set of 'purples pipes' distributing non-potable recycled water from local treatment works (Willis et al, 2011). Other sources of water that may be treated for non-potable reuse include 'sewer-mining' and 'stormwater mining' where water is abstracted from drainage pipes or intercepted before it arrives at the sewage treatment works or is discharged from stormwater drains.

Potable reuse is based on reverse osmosis, the same technology as desalination. Like desalination, it represents minimal disruption to conventional infrastructure arrangements, providing a new source of supply to meet growing demand or to replace over-abstracted water resources. Water as an industrial product can be endlessly recycled, as high tech membranes produce fresh water much quicker and more reliably than natural processes of hydrology. Potable reuse has the additional advantage over desalination of reducing wastewater discharges to the environment, relative to the additional supply. Projects are currently operating in the USA, Belgium, Germany, Namibia, the UK and Singapore, and new projects planned in Australia, the USA and the UK. The success of potable reuse projects depends largely on public acceptability, which varies depending on the level of public engagement during project development, the point of reintroduction of the recycled water into the 
drinking water resource (ground water, surface water or reservoir), and cultural differences between countries and communities.

Potable recycling has a contentious history in terms of public acceptability, with notable cases including the city of Toowoomba in Australia where a proposition for water recycling was rejected in a referendum in 2007, and San Diego in 2000 where a newly commissioned plant was shut down while public concerns about the environmental justice of poorer communities being supplied with recycled water were addressed (Hurlimann and Dolnicar, 2010). Despite being more costly and energy intensive in most cases, desalination is being more widely implemented than reuse, largely because it is less socially controversial than potable recycling (Dolnicar and Schaefer, 2009).

Public acceptability is widely recognised as a key consideration in pursuing potable reuse, but appropriate governance structures for debating and addressing public concerns have not yet been established (Colebatch, 2006; Hartley, 2006). The Toowoomba referendum provided a democratic opportunity for residents to decide whether or not to accept recycled water, which was soon undermined by the technical reality that the city was to be supplied from a regional network, which included recycled water from another catchment. The referendum forced debate into adversarial argument for or against a particular technology, leaving little room for addressing public concerns or evaluating alternatives within the design and decision making process. Democracy was presented as an afterthought to the technology, and proved expendable as the regional water shortage worsened. Promises that no city would receive recycled water without a referendum were withdrawn following the failure of the Toowoomba proposition during a worsening drought, and water management was withdrawn from democratic debate, despite clear public concerns about the technology (Hurlimann and Dolnicar, 2010).

Dual reticulated supply systems based on membrane processes to treat the wastewater for nonpotable require similar energy to treatment processes for potable use or brackish desalination (Cooley and Wilkinson, 2012). Membrane bioreactor treatment systems integrate wastewater treatment and membrane processes to produce water of suitable quality for non-potable reuse, with energy consumption lower than potable reuse and comparable to the sum of that required for conventional drinking water and wastewater treatment. MBR technologies displace the energy requirement for wastewater treatment, whilst most RO systems used for potable reuse treat the effluent from wastewater treatment, thus represent an additional energy expenditure. Dual reticulated systems can supply non-potable water using conventional, non-membrane tertiary 
treatment processes, such as anthracite filtration, UV disinfection and flocculation. Design and implementation of non-potable water supplies should also consider the embodied energy and carbon in additional piping and plumbing in full life cycle assessment of the environmental benefits in reducing pressure on water resources and the costs of additional materials and energy to construct and operate alternative systems (Cooley and Wilkinson, 2012).

Non-potable reuse of wastewater at development scale or for public and agricultural irrigation can be governed using similar arrangement to conventional water infrastructure, with non-potable quality standards and risk management procedures enforced by specific regulations and managed by water utilities. In Israel treated wastewater is distributed to farmers by Mekorot, the national water carrier. The Pimpama Coomera non-potable water supply in Queensland, Australia, is owned by local municipal utility Gold Coast Water. In London Thames Water supply non-potable water to the Stratford Olympic Park, which has been abstracted from the main sewer and treated before distribution in a dual pipe system. In each of these cases existing public health, environment and economic regulators are adapting to address the provision of a new infrastructure service by existing utility providers.

Development or neighbourhood scale non-potable resuse of municipal wastewater can simultaneously reflect a shared, localised responsibility for reducing impacts on local hydrological systems, and reinforce faith in expert-led technical systems to continue to meet demand for water despite scarcity. Non-potable supply provides and alternative means for users to meet their needs for water without depending on the potable mains supply. Whilst this can reduce demand on regional water supplies, it can be used to maintain high water using lifestyles, which may be ultimately unsustainable. This is particularly problematic where non-potable water systems are backed up or topped up with water from the potable supply. In the first dual reticulated housing development in Australia at Rouse Hill in Sydney, overall consumption of water increased when the scheme was first implemented, highlighting the importance of integrating water conservation and pricing with water recycling schemes (Livingston et al, 2005). When the non-potable system failed or were been used to capacity, the potable supply system provided backup, undermining potential savings.

\section{Decentralised non-potable supply}

The continuous supply of clean water throughout the city has been essential to delivering good public health. However, as water supplies are limited and the energy required to treat water and wastewater increases, the logic of using clean drinking water for flushing toilets, watering gardens 
and other low contact or non-critical functions is questionable. The move to fit-for-purpose water systems acknowledges that many of our needs can be met using water that does not meet drinking water standards. This then opens up the possibility for infrastructure systems and technologies that do not need the high standards of control and treatment required for drinking water, particularly if the source of water for such uses is relatively clean, compared to the reuse of highly contaminated municipal wastewater. A centralised, highly technocratic, strictly governed system may be required to continuously and reliably deliver high quality, safe water at low risk for the public to drink, or for reuse of wastewater. However, for less risky water uses from less contaminated sources, lower levels of control and treatment are required, allowing for more distributed approaches to the supply and management of water.

A decentralised approach to water utilises rainwater as a resource rather than constructing it as an urban drainage problem and recycles greywater using less energy intensive techniques than are required for wastewater reuse. Rainwater is essentially clean, except for biological, chemical and physical contaminants which deposit on roof or other runoff surfaces. Greywater is domestic wastewater excluding water from toilets. It is contaminated with domestic chemicals, skin cells, hair and other detritus, but is basically safe for non-potable reuse. Both sources of water are available across the city, and can be collected and treated in homes and buildings, or on a neighbourhood scale. Most attention to greywater reuse and rainwater harvesting is at household or building scale, with growing consideration of development scale reuse schemes.

Whilst saving water, rainwater harvesting and greywater reuse can be more energy and greenhouse gas intensive than conventional supply and reuse of municipal wastewater. In the UK it has been calculated that rainwater harvesting is more energy intensive and greywater systems less energy intensive than mains supply (Parkes et al, 2010). Energy use is highly dependent on the configuration of the system and the level of treatment desired. For rainwater harvesting energy use can be reduced by minimising pumping requirements, repositioning storage tanks, and reducing requirements for recirculation of water.

At building and household scale conventional governance arrangements for non-potable reuse are more difficult to apply than at development or urban scale. Rainwater harvesting can be as simple as a barrel on the end of a downpipe, and greywater reuse can begin with watering pot plants using dishwater. They can also involve complex systems of storage, treatment and reuse, including dual plumbing of houses and automated treatment and pumping systems supplied by international 
technology providers. More complex systems represent higher risk to the environment and public health and safety and may require some form of regulation.

A risk based approach to regulation of household and building scale recycling and harvesting of water is emerging, to recognise the variable complexity of technology and management systems. The Code of Practice for the Reuse of Greywater in Western Australia 2010 recognises different levels of technology and complexity in reuse systems, and applies variable levels of regulation of technology and use (Department of Health, 2010). Simple buckets and pipes used to redistribute laundry water for gardening can be used for immediate surface irrigation of gardens without storage, and do not require external monitoring or approval. Systems that store water for more than 24 hours must be provided by an approved supplier and can only be used for subsurface irrigation of gardens or for plumbed non-potable use. The requirement for approval of technologies has been criticised as increasing the cost of domestic reuse systems, restricting DIY innovation and encouraging complex treatment and pumping systems which require higher energy use. Requirements for subsurface irrigation have also been criticised as increasing costs unnecessarily in local environments with freely draining soils which are unlikely to pose any additional health risk from surface ponding of greywater.

Regulation of greywater reuse and rainwater harvesting in England and Wales relies on the judicious application of existing regulations applying to different aspects of water, plumbing and public health (Environment Agency 2010, 2011). Plumbing of greywater and rainwater systems must comply with water supply regulations and provide backflow protection to prevent contamination of potable supply. British Standard BS 85825 provides guidance on the design and monitoring on greywater systems. BS 8525 recognises different technical configurations of greywater systems, but begins with a level of complexity that requires technical expertise for design and installation, in contrast to the Western Australian Code of Practice which extends beyond these systems to provide guidance on home built systems and practices of reuse.

Decentralised non-potable supply provides and alternative means for users to meet their needs for water without depending on the centralised mains supply. Whilst this can reduce demand on regional water supplies, it can be used to maintain high water using lifestyles, which may be ultimately unsustainable. This is particularly problematic where non-potable water systems are backed up or topped up with water from the potable supply. Private individuals who invest in sophisticated rainwater harvesting or recycling systems may be less inclined to reduce their overall 
water use, which may be problematic when their private systems fail and are backed up by mains supply, as is required by the relevant British Standards (BSI, 2009; 2011).

Decentralised non-potable water systems maintain and disrupt elements of the conventional discourse of water infrastructure, and move closer to what might be considered a sustainable technical discourse. Water is constructed as a scarce resource. Water quality is assumed to be variable, rather than either pure or contaminated, and the risks associated with water quality are dependent on how it is stored, treated and used. Non-potable supply systems which are not backed up by potable supply enforce limits to natural resources. Basic household DIY systems use gravity and human energy, but more complex systems of treatment and pumping maintain dependence on a continuous, endless supply of energy. Embodied energy and materials in dual plumbing systems for houses and developments also maintain reliance on nature as resource and can have higher lifecycle environmental costs than conventional supplies.

Like water, technology is also recognised as being of variable complexity, depending on the source of water and how water is stored and used. Non-potable supply can be managed by lay people in their own homes and gardens, can be managed by third party service and technology providers, and can be managed by engineering based utilities. Consumers can become providers of water, and builders and managers of their own supply systems, or they can employ independent contractors to install and maintain water systems, independent of complex socio-technical water utilities.

Regulation and governance of water systems is in a state of flux. In Western Australia the levels of complexity of technology and the associated risk, with recognition that no government intervention is required for simple bucket and hose reuse, products and uses are regulated and restricted for more complex household systems, and conventional arrangements for infrastructure governance are appropriate at development or larger scale. In England and Wales government regulation relies on existing regulations and standards, with less formalised approaches to managing the particular risks and requirements for decentralised non-potable water.

Capital for non-potable supplies is also distributed across scales. For domestic systems the capital investment is made by the building owner, distributing water infrastructure capital to small scale owner-operators. The level of investment depends on the complexity of systems, but regulations requiring approved suppliers and technologies can inflate the cost of technology. 
Consumption of water remains a private matter, and individual ownership of non-potable supply systems can entrench neo-liberal constructions of society with individuals responsible for meeting their own needs for water. Alternatively, domestic scale supply of non-potable water represents an environmental ethic as individuals look to renegotiate their own relationship with water and nature outside conventional infrastructure arrangements.

\section{Water efficiency}

Reducing per capita and total consumption of water is an increasingly important element of urban water management. Demand management can take many forms including legal restrictions on water use, water metering and charging, education campaigns and improving the efficiency of water using appliances (Butler and Memon, 2005). Demand management activities are most common during periods of water stress, but are also important to achieve longer term, stable reductions in per capita water use.

Water metering has been shown to reduce demand by $10-15 \%$ in the UK (Herrington, 2005). Currently $37 \%$ of households in the UK are metered, with plans to rapidly implement more widespread metering in water scarce regions (Defra, 2011). Water metering allows consumers to measure and pay for the volume they use. With appropriate billing information, they can also see how their use changes over time or compares with average use in their local area. In order for water metering to have a significant impact on water demand it needs to be accompanied by appropriate water pricing. Rising block tariffs for instance have increasing charges per unit of water as the level of consumption increases. This still allows for basic needs to be met at a relatively low cost, but provides penalties for increasingly profligate use. Water charges might also be varied seasonally to allow utilities to charge more during times of water shortage to further encourage households to reduce their use.

The claims for water metering as a demand management measure need to be considered in the context of overall metering, behaviour change and housing stock. In the UK houses with meters tend to be newer, and where metering is at the discretion of the householder, meters tend to be installed by people who are already using less water than average or are inclined to change their behaviour to save money. Thus the early experience of high impact of metering as an isolated demand management measure are likely to be overstated, and it is now recognised that metering must be accompanied by strong customer engagement and water efficiency campaigns in order to achieve reductions in demand. 
Improving the efficiency of household appliances and fittings is important in water demand management (Waterwise, 2011). Education campaigns may be accompanied by provision of small water saving devices for users to install in their homes. These include cistern displacement devices, which can be placed in toilet cisterns to reduce the volume of water stored in the cistern and used each flush. Low flow shower heads are also a common device provided to households for free or at a subsidised price to reduce the flow rate of water from showers. More extensive demand management campaigns involve replacing existing fittings with more water efficient devices, such as the toilet replacement programme in New York which installed more than 1 million water efficient toilets in three years during in the 1990s (USEPA, 2002). Households can be encouraged or subsidised to replace existing washing machines and dishwashers with more water efficient models. Providing water efficiency information by labelling such devices is an important to allow consumers to take account of water efficiency in their purchasing, but this will only be one element of their purchasing decision.

Improving the water efficiency of appliances must not be at the expense of reduced performance, or there is a risk that overall water consumption will remain high. For instance, low flush toilets that do not clear the toilet bowl are likely to be flushed twice instead of once, and washing machines that do not rinse clothes properly may result in rinse cycles being run again. Design and installation of water efficient devices should also consider potential rebound effects. If people are aware that their appliances are water efficient they may use them more often, negating improvements in efficiency. For instance, if users know that their toilet has a low flush volume, they may flush it unnecessarily to dispose of household waste; they may be less reluctant to wash relatively clean clothes in a water efficient machine; and they may stand under their low flow shower for longer.

Water efficiency can also be promoted through building codes or standards for new buildings and major renovations. Plumbing standards that have previously been based on public health concerns are now being adapted to incorporate water efficiency measures. Specifications can apply to individual devices or fittings, or overall calculations of building water consumption, which allows designers flexibility in meeting overall standards for consumption. The UK Code for Sustainable Homes is an example of a building code which allows flexibility in how designers choose to meet set standards for water efficiency in new homes. In the Code, the overall per capita consumption of the house design is calculated based on the assumed use and performance of fittings, and the designer can choose between a range of water efficiency measures to meet standards required for different levels of rating in the Code scheme (DCLG, 2006). 
Water demand management strategies aim to reduce 'discretionary use' of water, reduce 'water wastage' and increase the efficiency of water using appliances. 'Discretionary use' is generally equated with outdoor water use - watering gardens, filling swimming pools, washing cars and hosing hard surfaces. In the summer of 2012 residents of London were unable to water their gardens due to a 'hose-pipe ban' and following a decade of low rainfall Melbourne is subject to 'permanent water saving rules' which ban hosing paved areas and restrict the hours of operation of automatic watering systems. The use of water indoors is taken for granted, and demand management campaigns are careful not to disrupt cultural norms that underpin water use in households. Demand management campaigns encourage people to take shorter showers or install water efficient shower heads, but do not question the 'need' for frequent showering or present alternative bathing practices, such as the 'flannel wash', that do not rely on large volumes of running water. Similarly public campaigns encourage people to only use their washing machines with a full load and provide industry standard labels to help consumers to choose to buy water efficient machines, but do not question the need to wash essentially clean clothes after every wear nor the desirability of individual ownership of washing machines. Whilst changing the cultures of gardening in dry environments such as Australia or Nevada is the subject of vigorous public discussion, changing cultures of cleanliness remains taboo ${ }^{2}$. Gardening is a semi-public activity, an outward expression of values, preferences, skill and creativity. Bathing and laundry are private and intimate, bodily functions that are presumed to be beyond the limits of public discourse. Gardening is open to discretion, discussing cultures of cleanliness is indiscrete.

Attention to individual behaviour, pricing and water efficient technologies in managing demand are useful starting points but fail to address the importance of relationships between technology, infrastructure, culture and consumption. Shove (2003) has demonstrated the importance of social and cultural expectations which shape everyday water using practices, and have co-evolved with technologies and infrastructures. Achieving significant, long term reductions in per capita demand for water requires redesigning water systems to account for the connections between culture, technology, infrastructure and water using practices. This requires reconfiguring infrastructure and

\footnotetext{
2 Southern Nevada Water District's 2006 water restrictions campaign included an award winning television commercial featuring 'Mrs Nuttington', an elderly woman kicking her neighbour in the groin for watering his lawn on the wrong day (available online http://www.youtube.com/watch?v=Lhpevdl2Sng, last accessed 30 June 2011). The campaign also included measures to pay residents to remove turf from their gardens and replace it with 'xeriscape' plantings and was highly successful in reducing water consumption in Las Vegas despite population growth.
} 
household systems to not only conserve water, but also to shift expectations and practices that lead to high water consumption.

Domestic water demand management is based on the premise that water is scarce and that all consumers should be involved in water conservation. However, by focussing on improving water efficiency, reducing water wastage and focussing on outdoor use, rather than fundamentally changing how we use water in our everyday lives, conventional demand management campaigns maintain the primacy of human 'need' for water over concerns about sustainability.

Demand management campaigns often construct nature as capricious, particularly during drought, and beyond the control of even the best engineering and management systems. Nature is also presented as under pressure from human exploitation in education campaigns that connect domestic water consumption to environmental impacts.

Water efficient technologies promise that current lifestyles can be maintained at the same time as reducing domestic water efficiency, and behaviour change campaigns focus on education of consumers about the value of water and how they can reduce wastage. Installing water efficient technologies can be the responsibility of the individual householder, water companies and builders. Water efficiency is governed through building codes and building assessment tools, water company targets set by regulators, and local government or environmental education campaigns.

Water metering, including smart metering, is a technology that aims to link water consumption and water cost to consumers. Water metering as a demand management measure assumes that consumers behave rationally and respond to more information about their water use, including price signals. This is an individualistic, neo-liberal model of human behaviour and decision making, which is uncontroversial within much engineering systems thinking, but does not fully account for the complexity and diversity of factors influencing how people use water.

The economics of demand management are contested. Whilst overall cost-benefit analysis may be used to demonstrate the benefit of investing in demand management rather than supply side options for addressing water shortages, profit-loss-asset balance sheets can lead to different economic drivers. Whilst investment in demand management may offset the need for capital investment in new supplies, it is usually considered an operating expense that does not lead to an increase in asset value of the water utility (Waterwise, 2008). Economic regulation and accounting 
are consequently highly influential in determining the level of spending on demand management by utilities. For utilities aiming to maximise capital value and minimise operating expenses, demand management may not be as attractive as investing in new supply options, despite overall costbenefits. Demand management reduces large scale capital investment, and distributes spending on new technologies and behaviour change throughout individual households.

Most demand management campaigns maintain social and spatial delineations between public and private. Outdoor water use is a public activity and is highly regulated in times of water shortage. Indoor water use is private and is subject to neo-liberal strategies including pricing, information provision and education to achieve greater efficiency of resource use and individual behaviour change.

\section{Water Sensitive Urban Design}

A shift towards working with water as a partner in urban design rather than an element to be controlled is most evident in recent developments in urban drainage (Karvonen, 2011). In recent decades approaches to the design of urban drainage systems have undergone radical transformation away from efforts to control flows of surface water towards working with natural hydrological flows and ecological systems. For most of the twentieth century urban drainage systems were dominated by heavy engineering, with their primary function being to remove water from the urban environment as quickly as possible to prevent flooding or standing water. Such fast conveyance systems require large underground pipes and drains which are either combined with urban wastewater or, in newer developments, are an entirely separate system of pipes which discharge into local water bodies (Butler and Davis, 2000).

Since the 1970s urban drainage systems have been under scrutiny as a source of pollution, detrimental to local aquatic systems (Brown et al, 2009). Separate surface water drainage systems discharge nutrients, oil and grease, heavy metals, solids and other pollutants washed from the urban environment. Combined surface and wastewater sewerage systems, such as in central London and Paris, treat the combined sewage resulting from normal rainfall events, but during heavy rainfall events the combined, untreated sewage overflows into the environment. The impacts of these discharges on aquatic ecosystems include eutrophication, deoxygenation, fish kills and accumulation of toxic metals and compounds in sediments, plants, fish and other animals. Storm water discharges and combined sewer overflows can also impact on the quality of drinking water resources for downstream settlements. 
The dominance of the fast conveyance approach to urban drainage and the associated degradation of urban rivers has also been apparent in the conversion of urban waterways to drains and culverts. Natural drainage lines provide the basis for engineering systems. Covering over streams and rivers has also provided space for urban development, particularly for road construction. The loss of urban rivers and associated biological diversity has become an issue of increasing concern to urban environmentalists.

In response to concerns about the environmental impacts of urban drainage systems, engineers and urban designers have devised new approaches to managing surface water. Water Sensitive Urban Design (WSUD) and Sustainable Urban Drainage Systems (SUDS) have emerged as efforts to mimic natural hydrological systems in urban environments. Rather than prioritising fast conveyance of surface water away from buildings, streets and urban spaces, WSUD and SUDS attempt to attenuate flows of storm water through the city and into the environment. Principles include increasing local infiltration of storm water into the ground, using local retention in buildings, green spaces, ponds and wetlands, and using ecological systems to treat water before it is finally discharged into the local environment. These techniques reduce peak flows of surface water, leading to a reduced frequency of combined sewer overflow events and reducing pressure on local waterways from high inflows of polluted storm water in separate systems (CIRIA, 2007).

Urban river restoration also reflects a changing approach to managing surface water in cities, which acknowledges the importance of urban aquatic environments and relinquishes ultimate engineering control of the system. In many cases this has involved the removal of concrete channels and restoration of rivers. Improving the quality of water discharged into these water courses is also important, through better control of industrial pollution as well as improved quality of storm water discharge and reduced frequency of combined sewer overflows. In some cities river restoration has resulted in relatively modest, gradual improvement in the local environment as concrete drains are returned to functioning ecosystems. In other cases it has involved dramatic transformation of the built environment and infrastructure, such as in Seoul where the restoration of the Cheonggyecheon River involved the removal of a major motorway and was central to a major urban regeneration scheme (Kang and Cervero, 2009).

WSUD and SUDS integrate green infrastructure and drainage infrastructure in cities, with potential benefits to surface water management, biodiversity, reduced urban heat island effects, and improved social amenity. Individual technologies and techniques can provide multiple benefits. For 
instance, green roofs attenuate surface water runoff, provide thermal insulation and can improve biodiversity. Rainwater harvesting provides a source of non-potable water supply and reduces surface water runoff to the urban drainage network. When integrated into high quality urban design and planning these features can also improve the social and cultural value of the urban environment, including the use of ponds for recreation as well as surface water detention, and the integration of ephemeral stream and swales into public spaces and housing development. Karvonen's (2010) study of the changing relationship to water and nature in Seattle focusses on changing approaches to surface water management consistent with SUDS and WSUD.

WSUD acknowledges the presence of water in the urban environment as a potential benefit rather than an absolute threat. WSUD works to protect and restore local watercourses and wetlands, and to construct them where needed to mimic the pre-development hydrological regime. Whilst working in partnership with natural water flows WSUD can also represent high quality urban design. The need to protect development from the risk of surface water flooding or unintended ponding is maintained in the WSUD approach, and the principle of local management of surface water and mimicking predevelopment hydrology generally do not represent naïve nostalgia for a return to purely 'natural' systems. Water is a part of the urban environment to be managed for the benefit of people and nature. Whilst there are some efforts to integrate WSUD and fit-for-purpose supply approaches, WSUD generally does not address water as a resource for human consumption. SUDS and WSUD measures are usually implemented separately to water and wastewater infrastructure.

The governance of WSUD and SUDS is currently evolving in many different jurisdictions. A key challenge for these systems is ownership and maintenance of assets. Conventional drainage systems have been managed as infrastructure networks with clear ownership and regulation structures, and demarcation between public and private responsibility for maintenance and repair. SUDS and WSUD measures are more dispersed across the built environment, involving a larger number of actors and owners. Implementing WSUD can be achieved through local flood planning and development planning, as a requirement for development or regeneration. Planning approvals can be used to require new developments to mimic the greenfields hydrology. SUDS and WSUD design standards have been developed to guide designers in how to achieve this (CIRIA, 2007).

WSUD and SUDS utilise techniques and technologies to reduce surface water runoff and mimic natural flow regimes. Technologies can include wetlands, ponds and ecological systems, as well as innovative 'hard' drainage technologies for slowing runoff, storing water and controlling flows. 
Where possible, technologies are passive and self-maintaining, or simple for owners to maintain. The design of SUDS and WSUD requires expert knowledge of hydrology and ecology, and requires classic design creativity and working with communities and clients.

Capital investment and operating costs are once again more dispersed in WSUD and SUDS approaches than in conventional urban drainage. Responsibility for building and maintaining features such as green roofs and rainwater harvesting may lie with the building owners, swales and ponds may be the responsibility of developers or local government, and the remaining conventional drainage system may remain the responsibility of drainage authorities and water utilities.

WSUD and SUDS approaches can be seen to highlight the connectivity within the urban environment, between buildings, public spaces, drainage networks, wildlife habitat and waterways. Designing urban environments as functioning hydrological systems breaks down the conventional out-of-sight-out-of-mind presumption about urban drainage. WSUD can bring all the benefits of good public realm design, together with improving water systems. WSUD and SUDs tend to focus on public realm design and external features of buildings and private gardens. It makes water more visible and present in the outdoor environment but makes little change to how water is used in private.

\section{Ecological sanitation}

In 2011 more than 2.6 billion people did not have access to basic sanitation (UN, 2011). Basic sanitation includes various forms of pit latrines and ecological sanitaiton as well as flush toilets. The Millennium Development Goal to halve the proportion of people without access to sanitation by 2015 will not be met. Provision of sanitation to those who do not have access in urban areas is complex and highly debated. Many advocates maintain that water based sewerage systems are the most effective technology for achieving good public health outcomes (Satterthwaite, 2008). The construction of water based sanitation systems in Europe, North American and other wealthy parts of the world, along with the provision of clean drinking water, is widely considered the greatest contributor to public health since the industrial revolution (BMJ, 2007). For many people working in urban development and public health, water based sanitation remains at the top of the 'sanitation ladder' as the ultimate goal for infrastructure provision, while waterless technologies are seen as merely the first step away from open defecation.

The goal of water based sanitation has been widely questioned, and is considered by many to be unachievable, unsustainable and undesirable (George, 2008; Langergraber and Muellegger, 2005). 
Water based sewerage systems require large scale capital investment, high standards of governance, robust financing for operating and maintenance, and continuous supply of water and electricity. In many cities the elements required for successful, centralised water based infrastructure do not exist. Growing awareness of limits to water resources and the environmental impacts of wastewater treatment and effluent discharge have also led to propositions for waterless sanitation in developed as well as developing countries. Waterless, ecological sanitation systems also improve options for recovery of energy and nutrients from the solid waste, compared with less efficient recovery from wastewater.

Ecological sanitation is promoted most strongly in rural areas. Outhouse superstructures can be built over latrine pits and moved when the pit is full, leaving the waste to decompose and be used as a fertiliser in nearby fields or gardens. Various designs for latrines and ecological sanitation systems have been developed, with an emphasis on locally available materials, use of local labour and engagement with local communities. The Community Led Total Sanitation movement began in Bangladesh and provides a structured methodology for engaging communities in the design and construction of their own ecological sanitation systems (Chambers, 2009).

The application of waterless sanitation to urban areas is more difficult. Space constraints makes pit emptying more difficult and dangerous, and higher population densities place additional pressure on the local environment and can increase public health risks. Addressing the challenge of devising a viable ecological sanitation system for urban areas has become a significant focus of design and development efforts. The Bill and Melinda Gates Foundation (2012) have run a high profile competition for universities to 're-invent the toilet' to deliver a standalone system that is not dependent on connections to electricity, water or a septic system, does not discharge pollutants and cost no more than 5 cents per day to run. Initiatives for urban ecological sanitation include the Kenyan social enterprise Sanergy, which manufactures standalone toilets with removable cartridges that are collected and emptied into biodigesters to produce renewable energy and fertiliser. Sanergy aims to develop a viable business model for provision of sanitation technology and services, together with nutrient and energy recovery.

Application of ecological sanitation in the developed world has largely been confined to remote and rural locations, including holiday homes and tourist sites. As interest in new toilet technologies and systems builds in the developing world, the possibility of long term reform of urban sanitation in wealthy cities is also being considered. London based designer Virginia Gardiner has developed the 
LooWatt system along similar lines to the Sanergy proposal, with removable waste cartridges delivered to local biodigester facilities. Widespread adoption of ecological sanitation in the developed world is unlikely in the foreseeable future, but may be part of a longer term transition to sustainable urban systems.

Ecological sanitation assumes water is a scarce resource that should not be contaminated with human waste. The recovery of energy and nutrients from shit reflects a broader concern for resource efficiency and reducing pollution of the environment. Keeping human waste out of the water and environment and recovering resources as within urban systems has the potential to significantly reduce human impact on the environment and represent a dramatic shift in how humans relate to the natural world. In most developed cities humans flush their shit away, for large public utilities to take care of before discharge back to the environment. In this way human bodily functions have large impacts on the environment, but these impacts occur at a distance and are mediated by large and complex socio-technical systems. Ecological sanitation systems have the potential to reconfigure the relationship between human bodily functions and environmental systems, using alternative socio-technical arrangements. Ecological sanitation, particularly as presented by Sanergy and LooWatt, provides opportunities for social enterprise and local economic activity based on provision of sanitation and resource recovery services. Regulation of such enterprises will require different governance arrangements to conventional systems, with the possibility for more actors to be involved. It will also require changes to public health regulations and planning, to allow for urban development served by ecological sanitation rather than the required connection to sewer. Implementing ecological sanitation systems with service providers emptying toilets may also lead to reconfiguration of domestic and urban space. Just as the removal of privies and the introduction of indoor flushing toilets changed the layout of urban and suburban housing, so too might houses and streets be reorganised once more to accommodate the shift towards ecological sanitation. 
Table 3. Technical discourses of water infrastructures

\begin{tabular}{|c|c|c|c|c|c|c|}
\hline & Desalination & Wastewater reuse & $\begin{array}{l}\text { Decentralised non- } \\
\text { potable }\end{array}$ & Demand management & Ecological sanitation & $\begin{array}{l}\text { Water Sensitive Urban } \\
\text { Design }\end{array}$ \\
\hline Water & $\begin{array}{l}\text { Endless } \\
\text { Industrial product }\end{array}$ & $\begin{array}{l}\text { Endlessly recyclable } \\
\text { Water cycle can be short } \\
\text { circuited }\end{array}$ & $\begin{array}{l}\text { Scarce } \\
\text { Multiple } \\
\text { Risky }\end{array}$ & $\begin{array}{l}\text { Scarce } \\
\text { Wasted }\end{array}$ & Scarce & $\begin{array}{l}\text { Part of the urban } \\
\text { landscapes } \\
\text { Flood risk }\end{array}$ \\
\hline Nature & $\begin{array}{l}\text { For human use } \\
\text { Energy is limitless } \\
\text { Outside city }\end{array}$ & $\begin{array}{l}\text { For human use } \\
\text { Energy is limitless } \\
\text { Outside city }\end{array}$ & $\begin{array}{l}\text { Humans part of water } \\
\text { cycles }\end{array}$ & $\begin{array}{l}\text { Constraint on resource } \\
\text { consumption }\end{array}$ & $\begin{array}{l}\text { Humans part of nutrient } \\
\text { cycles }\end{array}$ & $\begin{array}{l}\text { Part of urban landscape } \\
\text { Needs to be protected } \\
\text { from pollution }\end{array}$ \\
\hline Technology & $\begin{array}{l}\text { Complex } \\
\text { Engineer control } \\
\text { Centralised }\end{array}$ & $\begin{array}{l}\text { Complex } \\
\text { Engineer control } \\
\text { Centralised }\end{array}$ & $\begin{array}{l}\text { Simple to intermediate } \\
\text { complexity } \\
\text { Lay to engineer } \\
\text { controlled } \\
\text { Simple to complex } \\
\text { Decentralised and } \\
\text { intermediate scale }\end{array}$ & $\begin{array}{l}\text { Simple } \\
\text { Designer led } \\
\text { Inefficient or efficient } \\
\text { Consumer choice } \\
\text { Independent } \\
\text { behaviour } \\
\text { Decentralised } \\
\end{array}$ & $\begin{array}{l}\text { Simple } \\
\text { Lay expertise } \\
\text { Designer and community } \\
\text { led } \\
\text { Decentralised and } \\
\text { intermediate scale }\end{array}$ & $\begin{array}{l}\text { Simple to intermediate } \\
\text { complexity } \\
\text { Multi-disciplinary } \\
\text { expertise } \\
\text { Decentralised } \\
\text { intermediate scale to } \\
\text { Includes ecosystems } \\
\end{array}$ \\
\hline Society & $\begin{array}{l}\text { Demands water } \\
\text { Consumption is private } \\
\text { Accepts technology }\end{array}$ & $\begin{array}{l}\text { Demands water } \\
\text { Consumption is private } \\
\text { Accepts technology }\end{array}$ & Consumption is private & $\begin{array}{l}\text { Individuals consume } \\
\text { water } \\
\text { Attitudes and behaviours } \\
\text { Wastage and usage are } \\
\text { distinct }\end{array}$ & $\begin{array}{l}\text { Public health is } \\
\text { paramount }\end{array}$ & $\begin{array}{l}\text { Needs urban green space } \\
\text { and healthy waterways }\end{array}$ \\
\hline Governance & $\begin{array}{l}\text { Regulated utility } \\
\text { Municipal to national } \\
\text { governance } \\
\text { Technocratic }\end{array}$ & $\begin{array}{l}\text { Regulated utility } \\
\text { Municipal to national } \\
\text { governance } \\
\text { Technocratic, with } \\
\text { recognition of public } \\
\text { concerns }\end{array}$ & $\begin{array}{l}\text { Risk based regulation } \\
\text { depends on complexity } \\
\text { of technology }\end{array}$ & $\begin{array}{l}\text { Standards encourage } \\
\text { technology change } \\
\text { Targets part of utility } \\
\text { regulation } \\
\text { Legal restrictions on } \\
\text { some uses }\end{array}$ & $\begin{array}{l}\text { Minimal regulation or } \\
\text { governance beyond } \\
\text { installation } \\
\text { Some regulation of solids } \\
\text { disposal } \\
\text { Municipal scale }\end{array}$ & $\begin{array}{l}\text { Municipal and } \\
\text { development scale } \\
\text { Intersects with regulated } \\
\text { utility }\end{array}$ \\
\hline Capital & $\begin{array}{l}\text { Centralised } \\
\text { Public and private }\end{array}$ & $\begin{array}{l}\text { Centralised } \\
\text { Public and private }\end{array}$ & $\begin{array}{l}\text { Decentralised } \\
\text { intermediate scale }\end{array}$ & $\begin{array}{l}\text { Decentralised } \\
\text { Can offset centralised } \\
\text { utility capital investment } \\
\text { Private ownership of } \\
\text { technology } \\
\text { Some corporate or public } \\
\text { subsidies }\end{array}$ & $\begin{array}{l}\text { Decentralised } \\
\text { Minimal capital } \\
\text { requirement } \\
\text { Initial investment by } \\
\text { household, municipality } \\
\text { or other funded } \\
\text { programme }\end{array}$ & $\begin{array}{l}\text { Decentralised and } \\
\text { intermediate scale } \\
\text { Developer, municipality } \\
\text { and utility owned } \\
\text { Public and private }\end{array}$ \\
\hline Space & $\begin{array}{l}\text { Infrastructure invisible in } \\
\text { cities } \\
\text { Production } \\
\text { consumption } \\
\text { distinct }\end{array}$ & $\begin{array}{l}\text { Infrastructure invisible in } \\
\text { cities } \\
\text { Production } \\
\text { consumption } \\
\text { distinct }\end{array}$ & $\begin{array}{l}\text { Water collected, stored } \\
\text { and treated throughout } \\
\text { city } \\
\text { Consumption } \\
\begin{array}{l}\text { production } \\
\text { proximate }\end{array} \\
\end{array}$ & $\begin{array}{l}\text { Consumption spaces are } \\
\text { private, but subject to } \\
\text { neo-liberal strategies of } \\
\text { control }\end{array}$ & $\begin{array}{l}\text { Sanitation spaces require } \\
\text { connection to } \\
\text { agricultural spaces and } \\
\text { energy systems. }\end{array}$ & $\begin{array}{l}\text { Design space for water } \\
\text { City is natural and } \\
\text { hydrological system } \\
\text { Create connection } \\
\text { between surface and } \\
\text { ground water }\end{array}$ \\
\hline
\end{tabular}




\section{Conclusions}

Water infrastructure is one of the most important socio-technical systems underpinning the development and functioning of modern cities. The purpose of this paper has been to operationalise theoretical insights from urban, feminist and science and technology studies to enable a sociotechnical analysis of current trends and emerging technologies in water provision in cities. It used Andrew Feenberg's (2010) concept of the technical code as a framework for drawing critical theories of technology, cities and the environment into a schema for comparing current innovations with conventional systems and a normative ideal of sustainability.

Water systems are in the midst of an infrastructural revolution, with radical changes underway in their technical and ideological form. The paper has analysed the extent to which water infrastructures and technologies are moving closer or further away from sustainability, summarised in Table 3. Are we any closer to renegotiating an urban partnership with water, or are we reinforcing modern patterns of domination and submission? The answer is both.

Water itself is contested in different technical and ideological developments underway in water infrastructure. Membrane technologies used in desalination and recycling systems further entrench water as a natural resource to be purified for human use, using ever more sophisticated, industrial technologies. Non-potable water systems disrupt the dichotomous construction of water as either pure or contaminated and aim to match water quality with water use, with a recognition of differing associated risks to public and environmental health. Water efficiency measures materialise an understanding of water as a scarce resource, whilst maintaining the primacy of human demands and modern lifestyles over the need to live within natural limits. Ecological sanitation more firmly entrenches and alternate statement of water as a precious resource by eliminating its use altogether. Water Sensitive Urban Design comes closest to understanding water as a partner in the urban environment, but only in public or external spaces, not in the privacy of homes and bathrooms.

Water is an element of natural systems, but is not the only point of connection between nature and urban water infrastructure. Water infrastructure and technologies embody wider constructions of the relationship between cities, technology and nature (as described by authors such as Edwards, 2011; Gandy, 2004; and Haraway, 1991). The energy demands of water systems are a key point of intersection with wider concerns about the impact of human development on natural systems. Desalination and energy intensive reuse technologies perpetuate a ratcheting up of demand for 
energy, which is unsustainable given the current drivers for overall reductions in energy use alongside the shift to low carbon energy sources. Rainwater harvesting systems most clearly represent tradeoffs between energy and water conservation, demonstrating the complex technical and thermodynamic relationships at play in changing systems of provision. Water Sensitive Urban Design most strongly recognises the role of nature in urban environments and the possibility for design, planning and technology to facilitate a more harmonious relationship, but once more this is limited largely to the visible public realm and does not address longer material relationships between hydrological catchments and private water using practices. Ecological sanitation, with its emphasis on recovery of energy and nutrients reflects a 'closed-loop' urban metabolism, to minimise urban resource extraction and environmental pollution.

Changes in urban water infrastructure involve a dazzling array of technological innovations, ranging from do-it-yourself home recycling systems to leading edge material science and process control engineering for recycling and desalination plants. Decentralised non-potable water and domestic water efficiency most clearly demonstrates the opening up of technologies and technical expertise, away from the previously tight control of professional engineers working for or consulting to water utilities. An understanding of water as both scarce and multi-purposed allows for an easing of expert control over technology and water quality. Household technologies for recycling recognise that relatively clean, though impure, water is safe for many uses and does not require the same level of expert monitoring and technologically intensive treatment as water intended for bodily consumption. Water production and management of technologies is opening up to lay expertise. Membrane technologies, however, increase the technical complexity of water supply and extend the distance between experts and consumers. It is these technologies that have provoked the greatest public opposition, representing a significant disruption to traditional public trust in water utilities and their engineers.

Existing governance arrangements are adapting to incorporate new technologies and sources of water, where utilities are able to maintain their essential function as providers of water services, even as those services expand to include water recycling and desalination. However, public controversy over recycling and desalination indicate that further reform is needed to ensure robust, democratic decision making about future water infrastructure (Colebatch, 2006). New arrangements are emerging for technologies that operate at household and building scale, with new design standards being stabilised and applied alongside existing standards for plumbing and water quality. The balance between public and environmental safety, economic efficiency, individual autonomy 
and technical innovation is difficult to maintain in regulation of non-potable water systems that operate at smaller scales. Systems of governance that have evolved around technocratic, centralised utility provision are ill-suited to newer, more nimble technologies operating at different levels of complexity and spatial scales.

The redistribution of water technologies across the city to individual homes, buildings and neighbourhoods potentially represents a movement of capital investment away from large infrastructure. However, at the same time, investment in membrane treatment technologies intensifies capital investment in centralised supply, enhancing the profitability of engineering firms and technology provides, at the cost of higher water prices to consumers. Ownership and management of WSUD and SUDS systems remains unclear in many jurisdictions, with attribution of costs, benefits and value to be determined. Ecological sanitation models based on service provision provide opportunities for economic development and social enterprise based on local businesses servicing homes and communities, with low capital requirements.

The technologies reviewed demonstrate a multiplicity of new social arrangements alongside conventional relationship stabilised in conventional water systems. Household non-potable supply systems and water efficiency can simultaneously represent entrenchment of a neoliberal, individualist model of society or can reflect a new environmental and social ethic acknowledging collective interests. Technological, social and political change are all required to achieve sustainability, but a change in technological scale does not in itself determine changing social and political values or structures (Feenberg, 2010; Winner, 1986; van Vliet et al, 2005).

The modern social delineation between public and private remains strong in most of the reforms evident to date (Wajcman, 1991; Wilson, 1991). Water efficiency measures make some intervention in private bathrooms and toilets, but the strongest restrictions and most vigorous debate about water use concern outdoor water use. WSUD and SUDS change public relationships with surface water, but require no reconsideration about private water use. Ecological sanitation has the greatest potential to disrupt water use associated with the most private of bodily functions, and is the least feasible in developed cities at the current time. Water use remains firmly private, even as the internet and surveillance cameras have transformed concepts of privacy in other areas of modern life. Privacy is of course fundamental to human dignity when it comes to matters of hygiene and sanitation. Apart from public health implications, lack of privacy is one of the most horrifying aspects of open defecation as practiced by billions of people. However, wider discussion of our private 
practices of cleanliness, including bathing and laundry, and their connection to household technologies, cultural norms and the health of aquatic ecosystems, could help shift urban water discourse.

As long as public discussions about urban water systems stop at the water meter, opportunities for cultural transformation of water using practices will be overlooked. Opening up discussion of private practices in public may disrupt gendered construction of water systems and technologies, bringing greater prominence to 'softer' practices of sorting laundry alongside 'harder' analysis of membrane performance. It may also provide opportunities for new technologies and innovations in domestic systems, which have been seen as beyond the scope of concern of 'Big Water' engineers (Sofoulis, 2005). A shift in attention to the technologies and practices of domestic consumption, as important elements of infrastructures systems could represent a either the extension of neo-liberal discourses of individual responsibility and control, or it could reflect changing gender politics - opening up the hidden feminine world of private water practice to the public gaze of masculine engineering, thus transforming both (Wacjman, 1991).

Changes in urban water infrastructure are underway across different scales. Water Sensitive Urban Design is creating spaces for water in cities where once it was banished to drains and sewers. This in turn recreates spaces for nature in cities where previously it was removed or hidden. New spaces are being designed into homes, buildings and streets for non-potable supply as well as WSUD features. Ecological sanitation has the potential to reconfigure homes and streets just as the installation of indoor plumbing and the flush toilet led to the removal of outdoor privies did in the nineteenth and twentieth centuries. Yet once more existing arrangements are reinstated by domestic water efficiency and new potable supplies of water, the twin tracks of conventional infrastructure responses to water scarcity, with technological changes at both ends of the infrastructural pipe negating the need for more fundamental reorganisation of urban spaces.

A revolution is underway in urban water infrastructure, however a transition to sustainability is far from inevitable. Sustainability will not come about as more enlightened social and political values drive more efficient and ecologically aligned technology as some have hoped (Brown et al., 2009; Novotny et al., 2010). Unsustainably high water consumption is not simply a reflection of hedonistic social values but is baked into urban infrastructure and domestic technologies. Alternative technologies and discourses are emerging in urban water infrastructure, but are far from unified in the ideologies they stabilise. 
Planners, designers and policy makers concerned about sustainability should be wary of the technical inevitability of desalination, recycling and other systems which most powerfully reinstate conventional codes of domination and control of nature and separation of public concern from technical rationality. Renewably powered desalination is less harmful than carbon intensive desalination but it is not sustainable. Decentralised water systems embody assumptions about the limits to water resources, but can also be problematic as high users of energy and reinforcing a private right to water. Improving the efficiency of domestic water using technologies and appliances is unarguably important in achieving sustainability. Moving beyond water efficiency to open up discussions about water using practices and cultural norms holds greater potential for transforming water consumption and renegotiating the boundaries between public and private, masculine and feminine elements of water infrastructure and consumption. Water Sensitive Urban Design is widely championed by designers and planners as exemplifying a more sustainable approach to urban nature, providing a useful foundation for more moving beyond drainage into water supply and wastewater technology and discourse. Ecological sanitation is filling a basic necessity in developing cities and may be part of a longer term transition to sustainability in developed cities in the future. Eliminating water from sanitation and recovering resources from shit holds the potential to radically reorder relationships between bodies, urban spaces and nature.

Relationships between cities, technologies and water are shifting. The technical codes of urban water infrastructure show strengthening of the master-servant discourse and alongside movements towards partnership. The extent to which this balance falls in favour of sustainability over coming decades will be determined by political decisions as well as technical innovation. Urban planners, designers and engineers who are conscious of the discursive as well as technical nature of infrastructure will be best placed to act as honest-brokers to citizens, politicians and financiers as debates about sustainability move beyond efficiency and environmental protection. Urban infrastructures stabilise relationships between people, technology and nature. The future form of urban relationships to water are now open for renegotiation. 


\section{References}

Allen A., Dávila J. and Hofmann P. (2006) The peri-urban water poor: citizens or consumers? Environment and Urbanization 18(2) 333-335.

Allon F. and Sofoulis Z. (2006) Everyday water: cultures in transition Australian Geographer 37 (1) 45 55.

Bell S. (2009) The driest continent and the greediest water company: newspaper reporting of drought in Sydney and London International Journal of Environmental Studies 66 (5) 581589.

Bell S. (2012) Urban water systems in transition Emergence: Complexity and Organization 14 (1) 4457.

Bijker W. (1997) Of bicycles, bakelites and bulbs Cambridge: MIT Press.

Bill and Melinda Gates Foundation (2012) Water, sanitation and hygiene strategy overview, available online http://www.gatesfoundation.org/watersanitationhygiene/Documents/wsh-strategyoverview.pdf, last accessed $2^{\text {nd }}$ September 2012.

BMJ (2007) BMJ readers choose the 'sanitary revolution' as greatest medical advance since 1840 British Medical Journal 334111.

Brown R., Keath N. and Wong T. (2009) Urban water management in cities: historical, current and future regimes Water Science and Technology 59 (5) 847-855.

BSI (2009) Rainwater Harvesting Systems BS8515, London: British Standards Institution.

BSI (2011) Grey Water Systems BS 8525, London: British Standards Institution.

Butler D. and Davis M. (2000) Urban Drainage $2^{\text {nd }}$ edition, London and New York: Spon.

Butler D. and Memon F. (2006) Water Demand Management London and Seattle: IWA Publishing Chambers R. (2009) Going to Scale with Community Led Total Sanitation IDS Practice Paper Number 1, Brighton: Institute of Development Studies.

CIRIA (2007) The SUDS Manual London: Construction Industry Research and Information Association. Colebatch H. K. (2006) Governing the use of water: the institutional context. Desalination 187 (1-3) 17-27.

Cooley H. and Wilkinson R. (2012) Implications of Future Water Supply Sources for Energy Demands Alexandria VA: Water Reuse Research Foundation.

Defra (2011) Water for Life The Stationery Office Ltd, available online http://www.defra.gov.uk/environment/quality/water/legislation/whitepaper/, last accessed $29^{\text {th }}$ August 2012.

Department of Communities and Local Government (2006) Code for Sustainable Homes London: Communities and Local Government Publications, available online 
http://www.planningportal.gov.uk/uploads/code for sust homes.pdf, last accessed $1^{\text {st }}$ September 2012.

Department of Health (2010) Code of Practice for the Reuse of Greywater 2010 Perth: Government of Western Australia, available online http://www.public.health.wa.gov.au/cproot/1340/2/COP\%20Gretwater.pdf, last accessed $1^{\text {st }}$ September 2012.

Dolnicar S. and Schaefer A. (2009) Desalinated versus recycled water: public perceptions and profiles of the accepters. Journal of Environmental Management 90 (2) 888-900.

Doron U., Teh T. H., Haklay M. and Bell S. (2011) Public engagement with water conservation in the Lower Lea Valley, UK Water and Environment Journal 25 555-562.

Edwards (2011) Infrastructure and Modernity: Force, Time and Social Organization in the History of Sociotechnical Systems, Chapter 7 in Misa T., Brey P. and Feenberg A. (eds) Modernity and Technology Cambridge MA: MIT Press 185-226.

Environment Agency (2010) Harvesting rainwater for domestic uses: an information guide Bristol: Environment Agency, available online http://publications.environmentagency.gov.uk/PDF/GEHO1110BTEN-E-E.pdf, last accessed 2 ${ }^{\text {nd }}$ September 2012.

Environment Agency (2011) Greywater for domestic uses: an information guide Bristol: Environment Agency, available online http://publications.environmentagency.gov.uk/PDF/GEHO0511BTWC-E-E.pdf, last accessed 2 ${ }^{\text {nd }}$ September 2012.

Feenberg A. (1991) Critical Theories of Technology Oxford: Oxford University Press.

Feenberg A. (1999) Questioning Technology London and New York: Routledge.

Feenberg A. (2010) Between Reason and Experience Cambridge: MIT Press.

Gandy M. (2004) Rethinking urban metabolism: Water, space and the modern city City 8 (3) p. 363379.

Gandy M. (2005) Cyborg Urbanization: Complexity and Monstrosity in the Contemporary City International Journal of Urban and Regional Research 29 (1) p. 26-49.

Gandy M. (2008) Landscapes of disaster: water, modernity, and urban fragmentation in Mumbai Environment and Planning A 40 p. 108-130.

George R. (2008) The Big Necessity London: Portobello Books.

Gikas P. and Tchobanoglous G. (2009) The role of satellite and decentralised strategies in water resources management Journal of Environmental Management 90 (1) 144-150.

Haraway, D. (1991) Simians, Cyborgs and Women: the Reinvention of Nature. Free Association Books, London.

Haraway, D. (2000) How like a leaf: an interview with Thyrza Nichols Goodeve. London: Routledge. 
Hartley, T. (2006) Public perception and participation in water reuse. Desalination 187 (1-3) 115-126. Herrington, P. (2005), Critical Review of Relevant Research concerning the effects of charging and collection methods on water demand, different customer groups and debt, UKWIR, Report Ref. No. 05/CU/02/1

Hurlimann A and Dolnicar S. (2010) When public opposition defeats alternative water projects - The case of Toowoomba, Australia. Water Research 44(1) 287-297.

Illich I. (1986) $\mathrm{H}_{2} \mathrm{O}$ and the Waters of Forgetfulness London and New York: Marion Boyars.

Kaika M. (2005) City of Flows New York and Abingdon: Routledge.

Kang C. D and Cevero R. (2009) From Elevated Freeway to Urban Greenway: Land Value Impacts of the CGC Project in Seoul, Korea Urban Studies 46 (13) 2771-2794.

Karvonen A. (2010) Metronatural ${ }^{\mathrm{TM}}$ : Inventing and Reworking Urban Nature in Seattle. Progress in Planning 74 (4) 153-202.

Karvonen A. (2011) Politics of Urban Runoff Cambridge MA: MIT Press.

Kuhn T. (1962) The Structure of Scientific Revolutions Chicago: University of Chicago Press.

Langergraber G. and Muellegger E. (2005) Ecological sanitation - a way to solve global sanitation problems? Environment International 31 433-444.

Latour, B. (1991) Technology is society made durable, in J. Law, (ed.), A Sociology of Monsters: Essays on Power, Technology and Domination, Routledge, London, p. 103-131.

Latour B. and Woolgar S. (1979) Laboratory Life London: Sage.

Livingston D.J., Stenekes N., Colebatch H.K., Waite T.D. and Ashbolt N J. (2005) Governance of water assets: a reframing for sustainability Water August 19-23.

Marvin S. and Graham S. (2001) Splintering Urbanism London: Routledge.

Merchant C. (1990) The Death of Nature $10^{\text {th }}$ Anniversary Edition San Francisco: Harper.

Mies M. and Shiva V. (1993) Ecofeminsim Melbourne: Spinifex Press.

Mitcham (1994) Thinking Through Technology Chicago: University of Chicago Press.

Novotny V., Ahern J. and Brown P. (2010) Water Centric Sustainable Communities Hoboken NJ: Wiley

Parkes C., Kershaw H., Hart J., Sibille R. and Grant Z. (2010) Energy and Carbon Implications of Rainwater Harvesting and Greywater Recycling. Final Report, Bristol: Environment Agency.

Pike Research (2010) Desalination Technology Markets Research Report, available from www.pikeresearch.com, last accessed $29^{\text {th }}$ August 2012.

Plumwood V. (1993) Feminism and the mastery of nature New York: Routledge.

Rothausen S. and Conway D. (2011) Greenhouse-gas emissions from energy use in the water sector Nature Climate Change 1 210-219. 
Satterthwaite D. (2008) In praise of sewers New Internationalist Magazine Issue 414, 1 August, available online http://www.newint.org/features/2008/08/01/sewer-or-not/, last accessed $2^{\text {nd }}$ September 2012.

Schumacher E.F. (1974) Small is Beautiful $2^{\text {nd }}$ edition, London: Abacus.

Schwartz Cowan R. (1983) More Work for Mother New York: Basic Books.

Shiklomanov I. (1993) World freshwater resources, Chapter 2 in Gleik P. (ed) Water in Crisis Oxford University Press, Oxford and New York.

Shove E. (2003) Comfort, Cleanliness and Convenience Oxford: Berg.

Shiva V. (1989) Staying Alive London: Zed Books.

Sofoulis Z. (2005) Big Water, Everyday Water: A Sociotechnical Perspective Continuum: Journal of Media and Cultural Studies 19(4) 445-463.

Star S. L. (1999) The Ethnography of Infrastructure American Behavioural Scientist 43(3) 377-391.

Swyngedouw E. (2004) Social Power and the Urbanization of Water Oxford: Oxford University Press.

UN (2011) Millennium Development Goals Report New York: United Nations.

United States Environmental Protection Agency (USEPA) 2002. Case studies in water conservation

USEPA Office of Water, on-line

http://www.epa.gov/WaterSense/docs/utilityconservation 508.pdf, accessed 25 July 2011.

van Vliet B., Chappells H. and Shove, E. (2005) Infrastructures of Consumption London: Earthscan

Wajcman J. (1991) Feminism Confronts Technology Sydney: Allen and Unwin.

Warren K. (1987) Feminism and ecology: making connections, Environmental Ethics 9(1) 3-20.

Waterwise (2008) Evidence base for large-scale water efficiency in homes London: Waterwise.

Waterwise (2011) Evidence Base for Large Scale Water Efficiency: Phase II Final Report London:

Waterwise, available online http://www.waterwise.org.uk/data/resources/12/evidence-

base-report april-2011 final.pdf, last accessed $1^{\text {st }}$ September 2012.

Watson S. (2002) City A/genders. In Bridge G. and Watson S. (eds) The Blackwell City Reader Malden MA: Blackwell p. 290-296.

Willis R., Stewart R., Williams P., Hacker C., Edmonds S. and Capati G. (2011) Residential potable and recycled water end use in a dual reticulated supply system Desalination 272 (1-3) 201-211.

Wilson E. (1991) The Sphinx in the City Berkeley: University of California Press.

Winner L. (1986) The Whale and the Reactor Chicago: University of Chicago Press. 